Published in final edited form as:

Neuroscience. 2006 December ; 143(3): 739-755.

\title{
Electrophysiological characterization of neurons in the
}

\section{dorsolateral pontine REM sleep induction zone of the rat: intrinsic membrane properties and responses to carbachol and orexins}

\author{
Ritchie E. Brown $\S^{1}$, Stuart Winston ${ }^{2}$, Radhika Basheer ${ }^{2}$, Mahesh M Thakkar ${ }^{2}$, and Robert W. \\ McCarley $^{2}$ \\ 1 In Vitro Neurophysiology Section
}

2 Laboratory of Neuroscience, Harvard Medical School and VA Medical Center, 940 Belmont Str., Research 151-C, Brockton, MA, 02301, USA.

\begin{abstract}
Pharmacological, lesion and single-unit recording techniques in several animal species have identified a region of the pontine reticular formation (Subcoeruleus, SubC) just ventral to the locus coeruleus as critically involved in the generation of rapid-eye-movement (REM) sleep. However, the intrinsic membrane properties and responses of SubC neurons to neurotransmitters important in REM sleep control, such as acetylcholine and orexins/hypocretins, have not previously been examined in any animal species and thus were targeted in this study.

We obtained whole-cell patch-clamp recordings from visually identified SubC neurons in rat brain slices in vitro. Two groups of large neurons (mean diameter 30 and $27 \mu \mathrm{m}$ ) were tentatively identified as cholinergic (rostral SubC) and noradrenergic (caudal SubC) neurons. SubC reticular neurons (noncholinergic, non-noradrenergic) showed a medium-sized depolarizing sag during hyperpolarizing current pulses and often had a rebound depolarization (low-threshold spike, LTS). During depolarizing current pulses they exhibited little adaptation and fired maximally at 30-90 Hz. Those SubC reticular neurons excited by carbachol $(n=27)$ fired spontaneously at $6 \mathrm{~Hz}$, often exhibited a moderately sized LTS, and varied widely in size $(17-42 \mu \mathrm{m})$. Carbachol-inhibited SubC reticular neurons were medium-sized $(15-25 \mu \mathrm{m})$ and constituted two groups. The larger group $(\mathrm{n}=22)$ was silent at rest and possessed a prominent LTS and associated $1-4$ action potentials. The second, smaller group $(n=8)$ had a delayed return to baseline at the offset of hyperpolarizing pulses. Orexins excited both carbachol excited and carbachol inhibited SubC reticular neurons.
\end{abstract}

SubC reticular neurons had intrinsic membrane properties and responses to carbachol similar to those described for other reticular neurons but a larger number of carbachol inhibited neurons were found (>50\%), the majority of which demonstrated a prominent LTS and may correspond to PGO-on neurons. Some or all carbachol-excited neurons are presumably REM-on neurons.

\section{Keywords}

rapid-eye-movement; whole-cell; in vitro; sublaterodorsal; hypocretin; narcolepsy

\footnotetext{
All correspondence should be sent to: Ritchie E. Brown, Ph.D, In Vitro Neurophysiology Section, Laboratory of Neuroscience, Department of Psychiatry, Harvard Medical School VA, Medical Center Brockton Research, 151C, 940, Belmont St., Brockton, MA, 02301, USA Phone: 17748261892 Fax: 17748262259 Email: Ritchie_Brown@hms.harvard.edu Email addresses:

Ritchie_Brown@hms.harvard.edu, Stuart_Winston@hms.harvard.edu Radhika_Basheer@hms.harvard.edu,

Mahesh_Thakkar@hms.harvard.edu, Robert_McCarley@gms.harvard.edu.
} 


\section{Abbreviations}

ACSF Artificial cerebrospinal fluid; AHP Afterhyperpolarization; AP Action potential; CARB Carbachol; CARB-E Carbachol excited; CARB-I Carbachol inhibited; CCD Charge coupled device; ChAT Choline acetyltransferase; DAB Diaminobenzidine; DC Direct current; GABA Gammaamino-butyric acid; GAD67 glutamic acid decarboxylase $67 \mathrm{kDa}$ isoform; HCN Hyperpolarization activated and cyclic nucleotide gated cation channels; IACUC Institutional Animal Care and Use committee; IR-DIC Infra-red differential interference contrast; LC locus coeruleus; LDT laterodorsal tegmental nucleus; LTS low-threshold spike; mPRF medial pontine reticular formation; nNOS neuronal nitric oxide synthase; Ox A Orexin A; PGO pontine-geniculate-occipital waves; PnC pontine nucleus caudalis; $\mathrm{PnO}$ pontine nucleus oralis; P waves Pontine component of PGO waves; REM rapid-eye-movement; RMP resting membrane potential; sAHP slow afterhyperpolarization; sEPSPs spontaneous excitatory postsynaptic potentials; sIPSPs spontaneous inhibitory postsynaptic potentials; SubC Subcoeruleus (SubCD + SubCA); SubCA Subcoeruleus, alpha part; SubCD Subcoeruleus, dorsal part; TTP time-to-peak; TTX Tetrodotoxin; TyH Tyrosine hydroxylase; VGLUT2 vesicular glutamate transporter 2; vPNO ventral pontine nucleus oralis

Rapid-eye-movement (REM) sleep was discovered over 50 years ago by Aserinsky and Kleitman (Aserinsky and Kleitman, 1953). Since that time many investigators have sought to understand the brain mechanisms controlling this mysterious state whose function remains obscure. Early transection studies by Jouvet and coworkers in the cat identified the pons as being critical for REM sleep (Jouvet, 1962). Further investigation by the Jouvet group and others identified a region ventral to the locus coeruleus (LC), lateral to the midline and mediodorsal to the trigeminal motor nucleus which plays a critical role in at least two aspects of REM sleep, namely muscle atonia and PGO spikes (Mouret et al., 1967; Marks et al., 1980; Baghdoyan et al., 1984; Morrison, 1988; Yamamoto et al., 1990; Boissard et al., 2002). In the cat this region has been called the peri-LC, subcoeruleus alpha and subcoeruleus whereas in the rat it encompasses the regions termed dorsal subcoeruleus (SubCD) and subcoeruleus alpha part (SubCA) by Paxinos and Watson (Paxinos and Watson, 1998). Recently this same area in the rat has been termed the sublaterodorsal nucleus (SLD) by Boissard et al. (Boissard et al., 2002). In this manuscript we will use the term SubC to refer to this area, which is shown in figure 1.

A number of converging lines of evidence support the contention that the SubC is critical for the muscle atonia which occurs during REM sleep. Small electrolytic lesions of the SubC abolish REM muscle atonia in the cat and in the rat, whilst larger lesions lead to 'dream-like' behaviour (Mouret et al., 1967; Morrison, 1988; Sanford et al., 2001; Karlsson et al., 2005). Temporary inactivation of the SubC in the rat with tetrodotoxin (TTX) decreases the amount of REM sleep during the light (inactive) period although REM without atonia was not observed (Sanford et al., 2005). In the cat (Sakai and Koyama, 1996) or neonatal rat (Karlsson et al., 2005) neurons have been recorded in the SubC which fire tonically at increased rates just prior to and during the muscle atonia of REM sleep. Furthermore, electrical stimulation of the SubC in the decerebrate rat (Hajnik et al., 2000) elicits bilateral muscle atonia. Application of the cholinergic agonist carbachol to this area in the cat causes, at short latency, a pharmacologically induced state virtually indistinguishable from REM sleep, including the muscle atonia component (Mitler and Dement, 1974; Baghdoyan et al., 1987; Vanni-Mercier et al., 1989; Yamamoto et al., 1990). In the rat, carbachol does not normally cause a REM-like state when injected into the SubC but a state similar to REM can be induced by application of the $\mathrm{GABA}_{\mathrm{A}}$ receptor antagonists, bicuculline and GABAzine (Boissard et al., 2002; Pollock and Mistlberger, 2003). 
Inappropriate triggering of REM muscle atonia occurs in the sleep disorder, narcolepsy, which is caused by the loss of orexin/hypocretin containing neurons in the hypothalamus or by the loss of the type II orexin receptor (Taheri et al., 2002). Moderate to dense orexin projections to the locus coeruleus and neighbouring SubC region have been demonstrated (Peyron et al., 1998) and orexin receptors are present within the SubC (Greco and Shiromani, 2001). Thus, this is a likely region where orexins act to regulate muscle tone. Rats receiving infusions of the neurotoxin hypocretin2-saporin into the SubC in the rat have increased sleep during the dark period and increased limb movements during REM sleep (Blanco-Centurion et al., 2004) whereas injections of antisense oligonucleotides directed against the type II orexin receptor in the pontine reticular formation near the SubC cause cataplexy and increased REM sleep (Thakkar et al., 1999).

In addition to muscle atonia, the SubC area has been linked to the phasic synchronized neuronal discharges which precede and accompany REM sleep, known as PGO (Pontine-GeniculateOcciptal) waves. Neurons in the SubC area neighbouring the brachium conjunctivum fire synchronized bursts preceding and phase-locked to PGO waves (McCarley et al., 1978; Sakai and Jouvet, 1980; Steriade et al., 1990; Datta, 1997), the pontine component of which (P-waves) can be recorded in rats using low-resistance electrodes (Marks et al., 1980; Kaufman and Morrison, 1981; Datta et al., 1998). Small injections of carbachol into the SubC in the rat elicits an increase in the frequency of PGO waves which is correlated with a facilitation of learning and memory formation (Mavanji and Datta, 2003; Datta et al., 2004).

Previous in vitro intracellular recordings from reticular neurons in the pons have focused upon neurons located more medially and ventrally than the $\mathrm{SubC}$ in the nucleus pontine nucleus oralis (PnO) and pontine nucleus caudalis (PnC) (Greene et al., 1986; Gerber et al., 1989; Nunez et al., 1997). In addition, no data are available regarding the responses of SubC neurons in the rat to neurotransmitters involved in behavioural state control. Consequently, the present study performed whole-cell patch-clamp recordings from neurons visually identified in the SubC by infra-red differential interference microscopy (IR-DIC) and characterized their responses to the cholinergic agonist carbachol and the orexins/hypocretins. Portions of this work have been presented in abstract form (Brown et al., 2003a; Brown et al., 2003b; Brown et al., 2004).

\section{Experimental Procedures}

\section{Animals}

Sprague-Dawley rat pups were purchased from Charles-River laboratories (Wilmington, MA). Rat pups were housed together with a nursing female in the animal facility of the Brockton Division of The Boston VA Healthcare system. The experiments described here were carried out in accordance with the National Institute of Health Guide for the Care and Use of Laboratory Animals and were approved by the Institutional Animal Care and Use committee (IACUC) of the Boston VA Healthcare system (Protocol 125-B-0902). Animals not used in electrophysiological experiments were euthanised by $\mathrm{CO}_{2}$ inhalation and decapitated. All efforts were made to minimize the number of animals and their suffering.

\section{Slice preparation}

10-14 day old, male, Wistar rats were deeply anesthetized with isofluorane and then decapitated. One or two 200 or $400 \mu \mathrm{m}$ thick coronal brainstem slices were cut between -9.16 and -9.8 with respect to Bregma rostrocaudally (according to the atlas of Paxinos and Watson, 1998) using a vibroslicer (Campden Instruments, U.K). After slicing they were placed into artificial cerebrospinal fluid (ACSF) containing (in $\mathrm{mM}$ ) $124 \mathrm{NaCl}, 1.8 \mathrm{KCl}, 25.6 \mathrm{NaHCO}_{3}$, $1.2 \mathrm{KH}_{2} \mathrm{PO}_{4}, 2 \mathrm{CaCl}_{2}, 1.3 \mathrm{MgSO}_{4}$, and 10 glucose (Osmolarity $300 \mathrm{mOsm}$ ), saturated with 
$95 \% \mathrm{O}_{2} / 5 \% \mathrm{CO}_{2}$ for $\geq 1 \mathrm{~h}$ at room temperature before being transferred to the recording chamber (Warner Instruments $27 \mathrm{~L}$ ) at $32^{\circ} \mathrm{C}$, where they were constantly perfused with the same ACSF at a flow rate of $2-3 \mathrm{ml} / \mathrm{min}$. The solution was warmed by passing it through an inline heater (Warner Instruments). The temperature of the solution was kept constant by a temperature controller (TC-344B, Warner instruments) connected to the inline heater and receiving input from a thermistor placed in contact with the solution within the recording chamber.

\section{Recording setup}

The recording chamber is positioned under a Zeiss Axioskop $2 \mathrm{FS}$ plus microscope fitted with $\mathrm{x} 4$ air and $\mathrm{x} 40$ (or x63) water immersion objectives, a Hamamatsu C7500-50 (or ORCA-AR) infrared-sensitive CCD camera and an EXFO Excite-120 Fluorescence illumination system. The microscope is fitted with appropriate filters to provide the correct wavelengths of light for infra-red illumination and Lucifer yellow fluoroscence.

\section{Whole-cell recordings}

One slice was taken from the holding chamber and placed in the recording chamber and held in place by two plastic meshes. The SubC region was positioned in the centre of the field of view using the low power (x4) objective. Subsequently the slice was examined under the high power (x40 or x63) water immersion objective and a healthy neuron close to the surface of the slice selected for recording based on its appearance under infra-red differential interference (IR-DIC) microscopy. Patch pipettes (3-6 M $\Omega$, when filled with patch solution) were pulled from borosilicate glass (1B150F-4, World Precision Instruments, Sarasota, Florida, USA) and filled with an intracellular 'patch' solution containing in mM: potassium gluconate $130, \mathrm{NaCl}$ 5, $\mathrm{MgCl}_{2}$, HEPES 10, EGTA 0.1, $\mathrm{Na}_{2}$ ATP 2, NaGTP 0.5, MgATP 4, Spermine 1 (pH 7.25 with $\mathrm{KOH}, 280 \mathrm{mOsm}$ ). The patch pipette was held in place by an electrode holder (World Precision Instruments) containing an $\mathrm{AgCl}$ coated silver wire and equipped with a side port to allow pressure to be applied to the interior of the pipette. The pipette holder was attached to the headstage of a Multiclamp 700A amplifier (Axon Instuments). Initial experiments were conducted using an Axopatch 1D patch-clamp amplifier; since action potentials and other fast events can be distorted by this type of amplifier (Magistretti et al., 1996), these data were excluded from the final analysis. The headstage amplifier was attached to an Eppendorf Patchman NP2 joystick-controlled micromanipulator allowing movement of the electrode in 3 dimensions. Positive pressure was applied orally to the interior of the pipette via tubing applied to the side port of the pipette holder and maintained by closing a three way valve. Signals were digitized using a Digidata 1322A analog-to-digital data acquistion device (Axon Instruments) and recorded on a PC using pClamp 9.0 software. In current-clamp experiments signals were digitized at $20 \mathrm{kHz}$ and low-pass filtered at $10 \mathrm{kHz}$. In voltage-clamp experiments signals were digitized at $2 \mathrm{kHz}$ and low-pass filtered at $1 \mathrm{kHz}$, except when measurements of series resistance were made when a sampling rate of $40 \mathrm{kHz}$ and a low-pass filter of $10 \mathrm{kHz}$ were used.

The electrode was placed in the bath solution and the potential difference between the tip of the electrode and the $\mathrm{Ag} / \mathrm{AgCl}$ reference electrode (in contact with the bath solution) adjusted to zero. Current pulses ( $20 \mathrm{pA}, 20 \mathrm{~ms}$ ) were applied to the pipette every $40 \mathrm{~ms}$ to monitor the resistance of the electrode. The pipette was positioned near the selected neuron using the micromanipulator and then moved laterally until a dimple appeared on the surface of the neuron. At this point the positive pressure was released and the electrode retracted slightly. In successful cases at this point the electrode resistance increased dramatically either spontaneously or with the aide of slight suction applied to the interior of the pipette i.e a gigaohm seal formed between the electrode and the cell membrane. At this point the cell was photographed using the Hamamatsu infra-red CCD camera and the image stored in the computer using a frame grabber. Long and short-axis cell diameter was measured from these 
images; the scale of the images was calibrated using an image of a 25 micron standard calibration grid acquired under the same conditions. The amplifier was switched to voltageclamp mode and the potential maintained at $-100 \mathrm{mV}$. Capacitative transients due to the electrode were cancelled using the Multiclamp controller software. Brief pulses of suction were applied to the interior of the pipette to break the cell membrane under the pipette and obtain access to the whole cell (observed as a sharp negative shift in the holding current required to keep the potential at $-100 \mathrm{mV}$ ). Membrane potential measurements were adjusted for a -15 $\mathrm{mV}$ liquid junction potential between pipette and bath solutions (calculated using pClamp9 Software, Axon Instruments). Series resistance was assessed from the peak value of current produced by an application of small $(5 \mathrm{mV})$ voltage steps according to Ohms Law $(\mathrm{R}=\mathrm{V} / \mathrm{I})$. Recordings were accepted if the series resistance was $<30 \mathrm{M} \Omega$ and stable. Since fast events are filtered by the combination of the series resistance and cell capacitance (Spruston et al., 1994), action potential measurements were accepted from those recordings where the series resistance was lowest $(<15 \mathrm{M} \Omega$ ). Bridge balance was continuously maintained during currentclamp experiments. Continuous recordings of membrane voltage and current were made using a Gould TA11 chart recorder (Gould Electronics, Cleveland, USA) or using a MiniDigi 1A system and Axoscope 9.2 software (Axon Instruments) with a sampling frequency of $1 \mathrm{kHz}$.

\section{Characterization of intrinsic membrane properties of SubC neurons}

The intrinsic properties of SubC neurons under current-clamp or voltage-clamp were characterized as follows. In current-clamp experiments a series of $1 \mathrm{~s}$ long current steps were applied to the neuron via the recording pipette. The size of the first (hyperpolarizing) step was adjusted so that the negative peak of the membrane potential during the step reached -115 to $-120 \mathrm{mV}$. The delta step value was adjusted be one-fifth of this value i.e. if $-\mathrm{x} \mathrm{pA}$ were required to attain $-120 \mathrm{mV}$ then the size of each subsequent step (n) was $-\mathrm{x}+\mathrm{n}(|\mathrm{x}| / 5)$.After $\mathrm{n}=6$ steps were depolarizing (positive current injection) and action potentials elicited. The steps were continued until the firing rate did not increase further. The following parameters were determined (see table 1): Resting membrane potential (RMP, in spontaneously firing cells this was determined in the presence of tetrodotoxin), $R_{i n}$ (determined from the negative peak of the smallest hyperpolarizing current step according to Ohm's law $\mathrm{R}=\mathrm{V} / \mathrm{I}$ ), membrane time constant (tau, determined by fitting an exponential decay curve to the initial portion of the smallest hyperpolarizing current step. Membrane potential=negative peak of membrane potential* $\mathrm{e}(-\mathrm{t} / \mathrm{tau})), \%$ depolarizing sag (determined from the largest hyperpolarizing step as membrane potential just before the end of the step/peak negativity during the step); action potential width; action potential threshold; action potential height; action potential rise time; Afterhyperpolarization (AHP) amplitude (single action potential); slow AHP (sAHP) amplitude (after the largest depolarizing step); $f_{\max }$ (during last or penultimate depolarizing step - whichever is greater). In addition to these values we observed the response at the offset of the hyperpolarizing pulses to see if there is a smooth return to baseline or if there is a delay before the first action potential (indicative of an A-current) or a rebound depolarization (LTS, indicative of a T-type calcium current or delayed inactivation of H-current). The same series of steps were applied in the presence of the blocker of voltage-gated sodium channels, tetrodotoxin (TTX, $0.5 \mu \mathrm{M}$ ).

Voltage-clamp experiments were conducted in the presence of TTX. Neurons were clamped at -60 or $-75 \mathrm{mV}$ and stepped (for $1 \mathrm{~s}$ ) to potentials between -65 and $-120 \mathrm{mV}$ at $5 \mathrm{mV}$ intervals.

\section{Determination of the effects of bath-applied carbachol and orexins}

Whole-cell current clamp recordings were conducted as described above. Small $200 \mathrm{~ms}$ long hyperpolarizing current pulses were applied every $15 \mathrm{~s}$ to monitor membrane potential and 
input resistance. Orexin A $(500 \mathrm{nM})$, orexin B $(500 \mathrm{nM})$ and Carbachol $(10 \mu \mathrm{M})$ were bath applied.

\section{Drugs and statistics}

Drugs were purchased from Sigma (St. Louis, MO, USA). Stock solutions of drugs were prepared in distilled water at 1000 times their desired final concentrations and stored at $-20^{\circ}$ C. Drugs were bath applied. The rate of flow of ACSF was $2 \mathrm{ml} / \mathrm{min}$ and there was a dead time of $1 \mathrm{~min}$ before substances entered the slice chamber. Data are presented as mean \pm standard error of the mean. Data were analysed and graphed using Graph Pad Prism 3.0 software. Differences between the effect of orexin A and orexin B were assessed with Student's t-test.

\section{Immunohistochemistry}

In a subset of slices following a successful recording from a putative SubC noradrenergic neuron the patch pipette was quickly retracted (preserving the integrity of the neuronal membrane). A new whole-cell recording at room temperature was made from the same neuron from which the patch clamp recording had been made (neuron continuously visualized using IR-DIC) using a fresh patch pipette filled with patch solution (as above) containing $0.5 \%$ Lucifer Yellow. This allowed us to mark the recorded neuron with a high concentration of fluorescent dye, which facilitated subsequent post-hoc identification of the recorded neuron in the thick $(200 \mu \mathrm{m})$ slice. Following recording the slice was fixed by placing it in a $10 \%$ formalin solution for 1-48 hours. Fluorescent immunohistochemistry was performed using a primary mouse monoclonal antibody against Tyrosine hydroxylase (1:500; Chemicon International) and a streptavidin-Cy 3 conjugated secondary antibody (red) to identify putative noradrenergic neurons. Stained slices were examined on a Zeiss Axioplan 2 microscope and photographed using a sensicam digital camera and data acquisition system. Immunohistochemical procedures to try to identify putative cholinergic neurons as nNOS or ChAT positive were not definitive and hence further details of these procedures are not given. In a different subset of slices we included $0.5 \%$ biocytin in the patch pipette solution and attempted post-hoc immunohistochemistry for glutamic acid decarboxylase (GAD67) to identify GABAergic neurons in slices resectioned at 20 or 40 microns to facilitate GAD67 staining. Since only a very few biocytin-labeled cells were recovered and no cell tested with carbachol or orexins was positively identified as being GABAergic, these data are not presented.

\section{Results}

\section{General properties of the SubC area, characterization of putatively cholinergic and noradrenergic neurons}

When viewed under IR-DIC the density of neurons in the SubC area was much less than the neighbouring central gray area containing the locus coeruleus and laterodorsal tegmental nucleus, and immediately dorsal to the SubC. The density of neurons was higher in the rostral SubC ( -9.16 to $-9.30 \mathrm{~mm}$ with respect to Bregma) than in the caudal SubC ( -9.68 to -9.8 $\mathrm{mm}$ ). Neurons in the SubC area were more difficult to distinguish from the surrounding tissue (presumably due to more myelinated axons) than in the central gray. Identification became increasingly difficult with increasing animal age, necessitating the use of young (10-14 day old animals) in this study.

Previous immunohistochemical experiments, confirmed here (see below), have demonstrated that the SubC region of the reticular formation contains cholinergic and noradrenergic neurons (Paxinos et al., 1999), in addition to 'reticular' neurons. The electrophysiology and pharmacology of neurons in the neighbouring laterodorsal tegmental nucleus (LDT) and locus coeruleus (LC) (Williams et al., 1984; Wilcox et al., 1989; Luebke et al., 1992; Kamondi et 
al., 1992) were used to distinguish the putative cholinergic and noradrenergic neurons respectively from the non-cholinergic, non-noradrenergic 'reticular' neurons (see table 1).

Immunohistochemical staining for neuronal nitric oxide synthase (nNOS), which is a marker of cholinergic neurons in the brainstem revealed that scattered large nNOS positive neurons were present within the most rostral SubC areas (Fig. 1, -9.16 and -9.30 with respect to Bregma), just ventral to the laterodorsal tegmental nucleus (LDT). Accordingly, one group of very large (30.3 $\pm 1.6 \mu \mathrm{m}$ long-axis diameter), neurons encountered toward the rostral extent of the SubC region had properties similar to those of identified cholinergic neurons in the neighbouring LDT (Wilcox et al., 1989; Kamondi et al., 1992)(n = 19; Figure 2). These neurons were easily distinguished from the majority of SubC neurons by their size together with their distinctive electrophysiological properties. In particular, these neurons exhibited a prominent depolarizing sag during hyperpolarizing pulses (to $55.4 \pm 2.0 \%$ of peak, Fig. $2 \mathrm{~A}$, B). At the offset of hyperpolarizing pulses there was a rebound depolarization which elicited a single spike (Fig. 2A). In the presence of tetrodotoxin (TTX, $0.5 \mu \mathrm{M}$ ) to block voltage-gated sodium channels, a low-threshold spike was observed (Fig. 2B) which was substantially reduced by $500 \mu \mathrm{M} \mathrm{NiCl}_{2}(\mathrm{n}=3)$.

These putatively cholinergic neurons was strongly inhibited by carbachol (Figure 2C, E). In current clamp, in the presence of TTX $(0.5 \mu \mathrm{M})$, a brief ( $2 \mathrm{~min})$ application of carbachol (10 $\mu \mathrm{M})$ caused a hyperpolarization of $-8.6 \pm 1.2 \mathrm{mV}(\mathrm{n}=10)$. In voltage-clamp, carbachol caused a large outward current of $133 \pm 9 \mathrm{pA}(\mathrm{n}=4)$. Application of slow $(4 \mathrm{~s})$ ramps from -30 to $-110 \mathrm{mV}$ revealed the current induced by carbachol reversed at $-98.6 \pm 2.9 \mathrm{mV}(\mathrm{n}=4)$, close to the theoretical equilibrium potential for potassium under our conditions $(-100 \mathrm{mV})$. Similar to cholinergic neurons in the LDT (Luebke et al., 1992; Rainnie et al., 1994; Burlet et al., 2002), in the presence of TTX these neurons were excited by orexin A (Fig. 2D, $9.9 \pm 1.2 \mathrm{mV}$, $\mathrm{n}=3)$ and were hyperpolarized by application of serotonin $(100 \mu \mathrm{M}, \mathrm{n}=3)$ or adenosine (100 $\mu \mathrm{M}, \mathrm{n}=3)$.

Immunohistochemical staining for tyrosine hydroxylase revealed that scattered medium-tolarge sized TyH-positive neurons were present in the caudal SubC regions (Figure 1; -9.68 and -9.8 relative to Bregma) at the level of the main part of the LC. Occasional $(n=9)$, spontaneously firing $(1.0 \pm 0.3 \mathrm{~Hz})$, medium-to-large $(26.2 \pm 1.6 \mu \mathrm{m}$ long-axis diameter $)$, neurons encountered towards the more caudal extent of the SubC region lacked a depolarizing sag during hyperpolarizing current pulses (Fig. 3A). These neurons had other features which are also typical of noradrenaline neurons (Williams et al., 1984) including a shoulder on the falling phase of the action potential, a prominent A-current (Fig. 3B), large regenerative calcium spikes in the presence of TTX and were found to stain for TyH $(n=4$, Figure $3 \mathrm{C})$. In the presence of TTX $(0.5 \mu \mathrm{M})$, they were strongly hyperpolarized by noradrenaline $(100 \mu \mathrm{M}$, $-13.5 \pm 2.2 \mathrm{mV}, \mathrm{n}=3$ ) and were depolarized by application of carbachol (Fig. 3D, $10 \mu \mathrm{M}$, $10.8 \pm 1.7 \mathrm{mV}, \mathrm{n}=3)$. Application of orexin A $(500 \mathrm{nM})$ in the presence of TTX caused a depolarization $(8.4 \pm 1.7 \mathrm{mV}, \mathrm{n}=3)$ and large calcium spikes (Fig. 3E).

\section{Properties of SubC reticular neurons}

Recordings were made from 54 SubC neurons with properties dissimilar to the tentatively identified cholinergic and noradrenergic neurons; these were designated SubC reticular neurons (see methods). The measurements used to characterize the intrinsic membrane properties of the different types of SubC neurons are summarized in table 1. SubC reticular neurons varied in their size (15-42 $\mu \mathrm{m}$ long-axis diameter) and normally had an oval, triangular or fusiform shape. Their intrinsic membrane properties showed several general features. Firstly, these neurons exhibited little or no spike frequency adaptation during long ( $1 \mathrm{~s})$ depolarizing current pulses (Fig. 4). Secondly, the maximal firing frequency of most neurons was in the range $30-80 \mathrm{~Hz}$. With increasing depolarizing current the firing increased linearly 
up to around $30 \mathrm{~Hz}$ whereas monotonic increases in firing rate in cholinergic or noradrenergic neurons were only observed up until around $12 \mathrm{~Hz}$ (Fig. 4C). Thirdly, most neurons exhibited a modest depolarizing sag (65-90\% of peak amplitude at the end of 1 s hyperpolarizing pulse to potentials more negative than $-80 \mathrm{mV}$ ). In most neurons this sag could be fit with a single exponential with a time constant of several hundred milliseconds, whereas the sag in putative cholinergic neurons normally required two exponentials to obtain an adequate fit. In all neurons tested the rectification was blocked by a brief $(2 \mathrm{~min})$ application of $2 \mathrm{mM} \mathrm{CsCl}(\mathrm{n}=6)$ or a more prolonged $(15 \mathrm{~min})$ application of the selective H-current blocker ZD7288 $(50 \mu \mathrm{M}, \mathrm{n}=$ 3 , Fig 5D). In the presence of TTX $(0.5 \mu \mathrm{M})$ many neurons had a rebound depolarization at the offset of hyperpolarizing current pulses, which was completely or substantially blocked by the calcium channel blocker $\mathrm{NiCl}_{2}(500 \mu \mathrm{M}, \mathrm{n}=6$, Figs. 5B, 6D). A small residual depolarization remaining in the presence of $\mathrm{NiCl}_{2}$ was blocked by $\mathrm{CsCl}(2 \mathrm{mM})$ indicating that it was caused by slow deactivation of the channels mediating the depolarizing sag.

Small spontaneous excitatory synaptic potentials (sEPSPs) and larger spontaneous inhibitory synaptic potentials (sIPSPs) were observed in many neurons in the presence or absence of TTX. The sIPSPs reversed around the chloride equilibrium potential ( $-70 \mathrm{mV}$ under our conditions) and were blocked by application of the $\mathrm{GABA}_{\mathrm{A}}$ receptor antagonist bicuculline $(100 \mu \mathrm{M}, \mathrm{n}=$ 4).

\section{Responses of SubC neurons to the mixed cholinergic receptor agonist carbachol and the orexins}

We tested the response of SubC reticular neurons to bath application of carbachol $(10 \mu \mathrm{M})$, an agonist at both muscarinic and nicotinic cholinergic receptors, and the orexins (A and B, 500 $\mathrm{nM}$ ). Most SubC neurons began to respond to carbachol or orexins within 1-3 min of their application to the perfusion line and achieved their maximal response within $5 \mathrm{~min}$. If a neuron had not responded within $5 \mathrm{~min}$ it was considered to be unresponsive. Only those neurons which were excited (depolarization in current-clamp or inward current in voltage-clamp) or inhibited (hyperpolarization in current-clamp or outward current in voltage-clamp) by carbachol are considered further here.

\section{Neurons excited by carbachol (CARB-E neurons)}

24 neurons were excited by carbachol $(n=17)$ or had intrinsic membrane properties identical to those neurons that were excited by carbachol $(\mathrm{n}=7)$. These neurons varied widely in size (mean diameter $24.5 \pm 1.2 \mu \mathrm{m}$, range 17-42 $\mu \mathrm{m}$ ). Upon gaining access to the whole-cell these cells fired spontaneously at $6.1 \pm 0.7 \mathrm{~Hz}$ (Fig. 5A). During hyperpolarizing current pulses a moderate depolarizing sag $(75.1 \pm 2.1 \%$ of peak at the end of a $1 \mathrm{~s}$ step to $-120 \mathrm{mV})$ was present (Fig. 5D). At the offset of hyperpolarizing pulses the cells began firing again quickly (delay of $74 \pm 8 \mathrm{~ms}$ ) with an increased firing rate of $15.8 \pm 2.9 \mathrm{~Hz}$ for the first three action potentials, which gradually returned to baseline values in the several hundred milliseconds following the hyperpolarizing step. In the presence of TTX $(0.5 \mu \mathrm{M})$, a rebound depolarization (Low-threshold spike, LTS) was observed (Fig. 5B) which had an amplitude of $13.5 \pm 1.8 \mathrm{mV}$ and a time-to-peak (TTP) of $120 \pm 16 \mathrm{~ms}$.

In current clamp in the presence of TTX $(0.5 \mu \mathrm{M})$ carbachol caused a depolarization of $8.4 \pm$ $1.9 \mathrm{mV}(\mathrm{n}=10)$ and a small, variable increase in input resistance to $115 \pm 13 \%$ of control (n =3). In 4 neurons, the depolarization by carbachol was associated with the appearance of large amplitude calcium spikes (Fig. 5F). In voltage-clamp carbachol induced an inward current at a holding potential of $-75 \mathrm{mV}$ of $-25.4 \pm 6.4 \mathrm{pA}(\mathrm{n}=7)$. CARB-E Neurons were also strongly depolarized by orexin A $(500 \mathrm{nM}, 11.6 \pm 2.0 \mathrm{mV}, \mathrm{n}=5$, Fig. $5 \mathrm{E})$ or orexin B $(500 \mathrm{nM}, 10.4$ $\pm 2.3 \mathrm{mV}, \mathrm{n}=5$ ). The effect of orexin A was not significantly different from that of orexin $\mathrm{B}$. 


\section{Neurons inhibited by carbachol (CARB-I neurons)}

Two groups of reticular neurons were inhibited by carbachol. The first, major group of neurons (CARB-ILTS) were medium-sized neurons (Fig 6A; long-axis diameter: $20.3 \pm 0.6 \mu \mathrm{m}$ ) which were normally silent at rest ( 18 of 22 neurons; resting membrane potential $-65.4 \pm 1.5 \mathrm{mV}$ ) and exhibited moderate inward rectification during hyperpolarizing current pulses $(83.0 \pm 2.2$ $\%$ of peak at the end of a $1 \mathrm{~s}$ step to $-120 \mathrm{mV}$ ). In current-clamp at the offset of hyperpolarizing current pulses these neurons exhibited a large low-threshold spike, which triggered either a single sodium-dependent action potential or a burst of 2-4 action potentials with an intraburst frequency of $202 \pm 48 \mathrm{~Hz}(\mathrm{n}=5)$. In the presence of TTX, this low-threshold spike (20.0 \pm 1.7 $\mathrm{mV}$, time-to-peak $64 \pm 7 \mathrm{~ms}$ ) could be seen in isolation (Fig. 6C). Those neurons which fired bursts of action potentials had the largest LTS' (> $21 \mathrm{mV}$ ) Application of the calcium channel blocker $\mathrm{NiCl}_{2}(500 \mu \mathrm{M}, \mathrm{n}=4)$ substantially blocked the LTS (Fig. 6D).

In current-clamp in the presence of TTX $(0.5 \mu \mathrm{M})$ carbachol hyperpolarized these neurons by $-8.3 \pm 0.9 \mathrm{mV}(\mathrm{n}=15$, Fig. $6 \mathrm{~F})$. This hyperpolarization was associated with a decrease in input resistance to $80 \pm 5 \%$ of control $(\mathrm{n}=4)$. In voltage-clamp, carbachol induced an outward current of $41 \pm 18 \mathrm{pA}(\mathrm{n}=4)$. CARB-I LTS neurons were excited by orexin A $(6.8 \pm 1.7 \mathrm{mV}$, $\mathrm{n}=4$, Fig. $6 \mathrm{G})$ or orexin $\mathrm{B}(9.1 \pm 2.7 \mathrm{mV}, \mathrm{n}=4)$. The effect of orexin A was not significantly different from that of orexin $\mathrm{B}$.

One minor group (CARB-I A current, $\mathrm{n}=8$ ) of medium-sized SubC reticular neurons (Fig. 7A) fired spontaneously at $5.1 \pm 2.7 \mathrm{~Hz}$, had a moderate depolarizing sag $(82.4 \pm 1.3 \%$ of peak) and a delayed return to baseline firing $(240 \pm 35 \mathrm{~ms})$ at the offset of hyperpolarizing current pulses (Fig 7B). In voltage-clamp, a transient outward (A) current was observed at the offset of hyperpolarizing voltage steps (Fig. 7C). Four of these neurons were tested with carbachol in the presence of TTX and were found to be inhibited ( 3 in current-clamp, $-10.8 \pm$ $4.6 \mathrm{mV}, 1$ in voltage-clamp).

\section{Discussion}

This study is, to the best of our knowledge, the first in any species to report the intrinsic membrane properties of neurons in the subcoeruleus area of the brainstem reticular formation, which is thought to be a key area involved in the generation of REM sleep. It is also the first study in rodents to describe the responses of SubC neurons to the cholinergic agonist carbachol and the first to describe responses to the orexins/hypocretins, regulators of REM sleep whose loss results in the sleep disorder narcolepsy. The main results of this study are as follows. Firstly, neurons with similar size, intrinsic membrane responses and pharmacological responses as cholinergic neurons in the laterodorsal tegmental nucleus and noradrenergic neurons in the locus coeruleus were found within the rostral and caudal SubC regions respectively. Secondly, non-noradrenergic, non-cholinergic 'reticular' neurons had similar intrinsic membrane properties to those previously described for reticular neurons in other parts of the pontine reticular formation although their relative abundance was different. In particular, a large population of small-to-medium sized neurons exhibited a prominent low-threshold spike (LTS) which triggered either a single action potential or a high-frequency burst of action potentials. Thirdly, SubC neurons, especially those silent at rest and with a large amplitude LTS, were more subject to hyperpolarization by carbachol than neurons in other reticular areas. Fourthly, both carbachol excited and carbachol inhibited SubC reticular neurons were excited by the orexins.

\section{Cholinergic and noradrenergic neurons}

Previous immunohistochemical studies, confirmed here, have shown that the SubC area contains cholinergic neurons which stain for choline acetyltransferase (ChAT) or neuronal 
nitric oxide synthase (nNOS)/diaphorase and noradrenergic neurons which stain for tyrosine hydroxylase (Paxinos et al., 1999). Accordingly, it was not surprising that we found two groups of neurons which had properties consistent with their being cholinergic and noradrenergic. Although we were not able to identify with certainty the recorded putative cholinergic neurons as being nNOS or ChAT positive a number of observations suggest that they are in fact cholinergic neurons. These cells were large in size and were located mainly in the rostral part of the SubC region which abuts the ventral portion of the laterodorsal tegmental area which is rich in cholinergic neurons. Their electrophysiological properties were also similar to those described for identified cholinergic neurons in the LDT (Kamondi et al., 1992); they had a prominent depolarizing sag (the largest seen in any neurons in this region) during hyperpolarizing current pulses which was followed by a rebound depolarization (LTS). Under voltage-clamp both transient outward (A) and inward (T) currents could be observed. As expected, carbachol strongly hyperpolarized these cells in current-clamp recordings or caused a large outward current in voltage-clamp which reversed at the potassium equilibrium potential, consistent with the activation of somatodendritic muscarinic autoreceptors (Leonard and Llinas, 1994). As shown previously for cholinergic LDT neurons (Luebke et al., 1992; Rainnie et al., 1994; Leonard and Llinas, 1994; Burlet et al., 2002), these neurons were inhibited by adenosine and serotonin and excited by orexin A.

Another group of neurons had properties similar to noradrenergic locus coeruleus neurons including a lack of depolarizing sag during hyperpolarizing current pulses (the only neurons to show this) and a delayed return to baseline at the offset of these pulses, mediated by a transient outward (A) current (Williams et al., 1984). These neurons were positively identified as being noradrenergic based on their staining for tyrosine hydroxylase. Like LC noradrenaline neurons they were hyperpolarized by noradrenaline and were depolarized by carbachol (Egan and North, 1985) or by orexin A (Horvath et al., 1999).

\section{Intrinsic membrane properties of SubC reticular neurons}

Gerber and colleagues (Gerber et al., 1989) described three types of neuron in the medial pontine reticular formation based upon on their responses to current injection. Non-burst neurons had only a non-burst firing pattern; low-threshold burst neurons had either a lowthreshold burst pattern or a non-burst pattern and high-threshold burst neurons which had either a high-threshold burst pattern or a non-burst pattern. Excluding the classes of neurons which were tyrosine hydroxylase positive or had properties typical of cholinergic neurons, all of the SubC neurons we recorded had properties similar to the non-burst and low-threshold burst neurons of Gerber et al, which made up $91 \%$ of their sample. Thus, the intrinsic membrane properties of dorsolateral reticular neurons appear to be broadly similar to more medially situated reticular neurons. In contrast to medial reticular neurons, the low-threshold burst neurons we recorded were mostly medium sized $(15-25 \mu \mathrm{m})$ neurons whereas in the medial reticular formation ( $\mathrm{mPRF}$ ) they tended to be larger neurons with an average diameter of 37 $\mu \mathrm{m}$ (Gerber et al., 1989).

SubC neurons had a medium-sized depolarizing sag during long hyperpolarizing pulses which was blocked by $2 \mathrm{mM}$ caesium or by the more selective antagonist ZD7288 indicating that it was likely mediated by a hyperpolarization activated cation current (H-current). A similar sag can be observed in the earlier work by Gerber and colleagues in the mPRF (e.g. Fig 7A3 in (Gerber et al., 1989)), however at the time that those recordings were made the H-current had not been well characterized in mammalian neurons. More recently a depolarizing sag blocked by caesium has been described by Nunez and colleagues in a subset of neurons in the ventral pontine nucleus oralis (vPnO) (Nunez et al., 1997). Immunohistochemical and in situ hybridization studies indicate that of the $\mathrm{HCN}$ channels which are responsible for $\mathrm{H}$-currents, 
the HCN2 channel is the most prominent in the rat pontine reticular formation so this is a likely candidate to mediate this depolarizing sag (Notomi and Shigemoto, 2004).

At the offset of hyperpolarizing pulses most neurons displayed a rebound depolarization which caused an increased frequency of action potential firing. In the presence of TTX a prominent low-threshold spike was present which was also visible as a transient inward current following the offset of hyperpolarizing voltage steps in voltage-clamp. This low-threshold spike was substantially or completely abolished by the application of the calcium channel antagonist nickel. Similarly, it was shown in mPRF neurons that the LTS was blocked by removal of extracellular calcium or high magnesium concentrations (10 mM) (Greene et al., 1986; Gerber et al., 1989). The size of this depolarization was larger and had a faster time-to-peak in CARBI neurons than in CARB-E neurons and in some of these CARB-I neurons a high-frequency burst of action potentials was triggered. A small group of neurons exhibited a delayed return to baseline at the offset of hyperpolarizing current pulses and a transient outward current in voltage-clamp similar to cells found in the ventral PnO (Gerber et al., 1989; Nunez et al., 1997).

During depolarizing current pulses SubC reticular neurons fired in a tonic fashion with little reduction in firing rate during the pulse, as seen in other reticular areas (Gerber et al., 1989; Nunez et al., 1997). Thus, it seems that they lack the calcium-activated potassium channel responsible for this property in hippocampal and neocortical pyramidal neurons (Lancaster and Adams, 1986).

\section{Responses to carbachol}

Previous in vitro intracellular studies in the nucleus pontis oralis or caudalis have shown that approximately one fifth to one-third of the neurons are inhibited by carbachol (Greene et al., 1989; Nunez et al., 1997) whereas the remainder are depolarized. In contrast we show here that $>50 \%$ of SubC neurons are inhibited by carbachol. As observed previously in reticular neurons, these hyperpolarizations were associated with decreases in input resistance (Gerber et al., 1991; Nunez et al., 1997), consistent with carbachol activating an inwardly rectifying potassium conductance (Gerber et al., 1991).

The neurons which were inhibited by carbachol were mainly of the low-threshold burst type. They were the only neuronal subtype in this area which showed bursting behaviour, leading us to propose, as has been previously suggested for neurons of this type in the MPRF (Greene et al., 1986), that these neurons are PGO-burst neurons. Their inhibition by acetylcholine during REM sleep will de-inactivate their low-threshold calcium current and allow them to fire single spikes or a burst of action potentials when receiving excitatory input, which may originate from long-lead PGO related neurons in the dorsal mPRF (McCarley and Ito, 1983; Pare et al., 1990) and/or the caudoventral pontine tegmentum (Vanni-Mercier and Debilly, 1998). In the cat, PGO burst neurons with a short lead time $(<100 \mathrm{~ms})$ prior to P-waves have been recorded in the parabrachial region which borders and overlaps with the subcoeruleus area recorded in this study in the rat (McCarley et al., 1978; Sakai and Jouvet, 1980; Nelson et al., 1983; Steriade et al., 1990; Datta and Hobson, 1994). Although neurons with these properties have also been recorded in other areas of the brainstem reticular formation, they seem to be particularly concentrated in the SubC area, which is consistent with this area being the best site to record P-waves (Marks et al., 1980; Farber et al., 1980; Kaufman and Morrison, 1981) and the most sensitive site for carbachol to cause an enhancement of P-wave frequency (Datta et al., 1998).

The stereotyped nature of the bursts in PGO burst neurons led Steriade and colleagues to conclude that the bursts were mediated by a low-threshold calcium spike of the type we have demonstrated here (Pare et al., 1990). These authors speculated that the hyperpolarization 
necessary for de-inactivation of the LTS would come from the substantia nigra pars reticulata GABA neurons (Datta et al., 1991b). However, since we have shown that these neurons are hyperpolarized by carbachol and it has been previously demonstrated that carbachol causes a long-lasting enhancement of PGO waves in both rats and cats (Datta et al., 1991a; Datta et al., 1998) we suggest that this hyperpolarization is likely to be caused by acetylcholine released from neighbouring cholinergic neurons in the laterodorsal tegmental nucleus (LDT). This would also be consistent with the block of carbachol induced PGO waves in the cat by a $\mathrm{M}_{2}$ receptor antagonist (Datta et al., 1993) since activation of $\mathrm{M}_{2}$ receptors usually causes a hyperpolarizing response similar to the one we have observed here (Egan and North, 1986; Gerber et al., 1991). Since our recordings were performed in vitro we have no way of knowing if these neurons really correspond to PGO burst neurons, however, if our speculations are correct then a number of testable predictions can be made. Firstly, infusions of bicuculline into the SubC, which cause muscle atonia and other REM phenomena (Boissard et al., 2002; Pollock and Mistlberger, 2003), will not cause P waves since the PGO-burst neurons will be depolarized, causing inactivation of the LTS. A similar prediction would hold for glutamate receptor agonists. Secondly, infusions of muscarinic $\mathrm{M}_{2} / \mathrm{M}_{4}$ receptor antagonists into the rat $\mathrm{SubC}$ will block spontaneously occurring P-waves. Thirdly, infusions of orexins into the SubC will block P-waves since we have shown that orexins depolarize this group of neurons. Loss of this orexinergic effect in narcolepsy may lead to enhanced PGO-waves and contribute to hallucinations experienced by narcoleptic patients (Taheri et al., 2002) since PGO-waves have been linked to the generation of dreamlike imagery (McCarley et al., 1983; Amzica and Steriade, 1996).

Many neurons in the SubC area were excited by carbachol. The carbachol excitation was associated with an increase in input resistance consistent with findings in the mPRF, that carbachol inhibits a leak potassium conductance (Greene et al., 1989). Carbachol excited neurons varied widely in size but were mainly medium to large cells. In preliminary experiments, we have found that 2 of these cells express the mRNA for the vesicular glutamate transporter 2 (VGLUT2) suggesting that they are glutamatergic (Brown et al., 2004). Since brainstem acetylcholine neurons projecting to the reticular formation increase their activity levels during REM sleep (reviewed in (McCarley, 2004) we believe that CARB-E SubC reticular neurons are likely to be REM-on (muscle-atonia ON) cells. In the cat, infusion of carbachol into the SubC reliably elicits a REM-like state (Baghdoyan et al., 1987; VanniMercier et al., 1989; Yamamoto et al., 1990) but this effect has been difficult to reproduce in the rat (Gnadt and Pegram, 1986; Bourgin et al., 1995; Deurveilher et al., 1997; Boissard et al., 2002). In contrast, infusion of $\mathrm{GABA}_{\mathrm{A}}$ receptor antagonists or glutamatergic agonists into the rat SubC did lead to a REM-like state being generated (Boissard et al., 2002 Pollock and Mistlberger, 2003).

In terms of their cellular actions, $\mathrm{GABA}_{\mathrm{A}}$ receptor antagonists and glutamatergic agonists are likely to activate all the different classes of neurons located in the SubC and surrounding areas whereas, as we have shown here, carbachol has both excitatory and inhibitory effects, including a very strong inhibition of cholinergic neurons. The rat brain is considerably smaller than the cat brain and it is likely to be difficult to restrict the injection in the rat to solely the SubC area. We suggest that carbachol inhibition of neighbouring LDT cholinergic neurons in the rat following injections targeted at the SubC may prevent the induction of a REM-like state in this species. This could be tested by measuring acetylcholine levels in the SubC when infusions of carbachol or bicuculline are made. In the cat, acetycholine levels rise following carbachol infusions in the pons close to the SubC region (Lydic et al., 1991). 


\section{Responses to orexins}

Orexins were found to excite all the different types of neurons in the SubC region including CARB-E neurons, which we believe are likely to be REM-on/Muscle atonia-ON neurons. This is surprising since narcolepsy (where orexins neurons are lost) involves two symptoms, cataplexy and sleep paralysis, which appear to represent the inappropriate turning on of REM muscle atonia. Since this is an in vitro study we cannot be sure that CARB-E, orexin excited neurons are REM, muscle atonia-ON neurons, however, this interpretation would be consistent with the paradoxical results of Kiyaschenko et al. who found that injection of orexins into the pontine inhibitory area (subcoeruleus region) of decerebrate rats caused muscle tone inhibition (Kiyashchenko et al., 2001). It would also fit with the results of Xi et al., who found that injections of orexins into the $\mathrm{PnO}$ close to the subcoeruleus region in cats excited reticular neurons recorded intracellularly and led to a state of active (REM) sleep with motor inhibition (Xi et al., 2002; Xi and Chase, 2006). Presumably, the direct orexin excitation of these neurons is overwhelmed in vivo by orexin excitation of GABAergic neurons projecting to and inhibiting these same SubC neurons (e.g. those in the midbrain locomotor region (Takakusaki et al., 2005). Interestingly, apparently contradictory effects of orexin are also observed in the raphe nucleus, where orexins directly excite wake-on, REM-off serotonin neurons but at the same time increase inhibitory input to these neurons (Brown et al., 2001; Liu et al., 2002). Thus, it is likely that orexins do not act to prevent cataplexy and sleep paralysis by acting preferentially at one brainstem site but rather their action depends on complex network effects throughout the brainstem and elsewhere in the CNS (Brown, 2003).

We present here the results obtained from in vitro recordings of neurons in a REM-related area of the pontine reticular formation from rat pups aged 10-14 days old. The relevance of our results for the mechanisms underlying REM obviously depend to what extent the active sleep in pups is similar to REM sleep in adults. Until recently it was thought that active sleep only begins to resemble adult REM sleep at around postnatal day 12 in rats when sleep-like states occurring simultaneously with low-voltage fast activity in the cortex can be recorded (Frank and Heller, 1997). More recently, however, experiments from Blumberg and coworkers have shown that most of the characteristic REM properties, including muscle atonia interrupted by brief myoclonic twitches and rapid-eye-movements can be observed by postnatal day 8 (Seelke et al., 2005; Karlsson et al., 2005). Furthermore, the same pontine and medullary sites observed to be important in the adult are involved in these phenomena in the neonate (Karlsson et al., 2005; Karlsson and Blumberg, 2005). Thus, we believe that our results can be considered relevant for models of REM sleep generation.

Since this is an in vitro study we cannot say with any certainty whether the different groups of neurons we have recorded from are PGO-related, muscle-atonia related or not related to REM sleep. However, the properties of the neurons, together with their pharmacological responses to carbachol and orexins both allow testing of current models and predictions to be made regarding the role that they may play in REM sleep control which are testable in future experiments in intact animals.

\section{Acknowledgements}

This work was supported by the veterans administration and by NIMH R01 MH062522 and NIMH R37 MH039683 (to R.W.M.). We would also like to thank Ivana Gritti (Milan, Italy) for assistance with GAD67 immunohistochemistry.

\section{References}

Amzica F, Steriade M. Progressive cortical synchronization of ponto-geniculo-occipital potentials during rapid eye movement sleep. Neuroscience 1996;72:309-314. [PubMed: 8737401]

Aserinsky E, Kleitman N. Regularly occurring periods of eye motility, and concomitant phenomena, during sleep. Science 1953;118:273-274. [PubMed: 13089671] 
Baghdoyan HA, Rodrigo-Angulo ML, McCarley RW, Hobson JA. Site-specific enhancement and suppression of desynchronized sleep signs following cholinergic stimulation of three brainstem regions. Brain Res 1984;306:39-52. [PubMed: 6466986]

Baghdoyan HA, Rodrigo-Angulo ML, McCarley RW, Hobson JA. A neuroanatomical gradient in the pontine tegmentum for the cholinoceptive induction of desynchronized sleep signs. Brain Res 1987;414:245-261. [PubMed: 3620930]

Blanco-Centurion C, Gerashchenko D, Salin-Pascual RJ, Shiromani PJ. Effects of hypocretin2-saporin and antidopamine-beta-hydroxylase-saporin neurotoxic lesions of the dorsolateral pons on sleep and muscle tone. Eur J Neurosci 2004;19:2741-2752. [PubMed: 15147308]

Boissard R, Gervasoni D, Schmidt MH, Barbagli B, Fort P, Luppi PH. The rat ponto-medullary network responsible for paradoxical sleep onset and maintenance: a combined microinjection and functional neuroanatomical study. Eur J Neurosci 2002;16:1959-1973. [PubMed: 12453060]

Bourgin P, Escourrou P, Gaultier C, Adrien J. Induction of rapid eye movement sleep by carbachol infusion into the pontine reticular formation in the rat. Neuroreport 1995;6:532-536. [PubMed: 7766858]

Brown RE. Involvement of hypocretins/orexins in sleep disorders and narcolepsy. Drug News Perspect 2003;16:75-79. [PubMed: 12792667]

Brown RE, Basheer R, Thakkar MM, Winston S, McCarley RW. In vitro electrophysiology of rat subcoerulean neuron. Sleep 2004;A27[(Abstracts)], A59

Brown RE, Sergeeva O, Eriksson KS, Haas HL. Orexin A excites serotonergic neurons in the dorsal raphe nucleus of the rat. Neuropharmacology 2001;40:457-459. [PubMed: 11166339]

Brown RE, Thakkar MM, McCarley RW. Whole cell patch-clamp recording from subcoerulean nucleus in vitro: effects of carbachol and orexins. Sleep 2003a;26:A10.[(Abstracts)]

Brown RE, Winston S, Thakkar MM, McCarley RW. Characterization of the electrophysiology and pharmacology of rat subcoerulean neurons. Soc Neurosci Abs 2003b;932.1

Burlet S, Tyler CJ, Leonard CS. Direct and indirect excitation of laterodorsal tegmental neurons by Hypocretin/Orexin peptides: implications for wakefulness and narcolepsy. J Neurosci 2002;22:28622872. [PubMed: 11923451]

Datta S. Cellular basis of pontine ponto-geniculo-occipital wave generation and modulation. Cell Mol Neurobiol 1997;17:341-365. [PubMed: 9187490]

Datta S, Calvo JM, Quattrochi JJ, Hobson JA. Long-term enhancement of REM sleep following cholinergic stimulation. Neuroreport 1991a;2:619-622. [PubMed: 1756243]

Datta S, Curro DR, Pare D, Oakson G, Steriade M. Substantia nigra reticulata neurons during sleepwaking states: relation with ponto-geniculo-occipital waves. Brain Res 1991b;566:344-347. [PubMed: 1814553]

Datta S, Hobson JA. Neuronal activity in the caudolateral peribrachial pons: relationship to PGO waves and rapid eye movements. J Neurophysiol 1994;71:95-109. [PubMed: 8158244]

Datta S, Mavanji V, Ulloor J, Patterson EH. Activation of phasic pontine-wave generator prevents rapid eye movement sleep deprivation-induced learning impairment in the rat: a mechanism for sleepdependent plasticity. J Neurosci 2004;24:1416-1427. [PubMed: 14960614]

Datta S, Quattrochi JJ, Hobson JA. Effect of specific muscarinic M2 receptor antagonist on carbachol induced long-term REM sleep. Sleep 1993;16:8-14. [PubMed: 8456236]

Datta S, Siwek DF, Patterson EH, Cipolloni PB. Localization of pontine PGO wave generation sites and their anatomical projections in the rat. Synapse 1998;30:409-423. [PubMed: 9826233]

Deurveilher S, Hars B, Hennevin E. Pontine microinjection of carbachol does not reliably enhance paradoxical sleep in rats. Sleep 1997;20:593-607. [PubMed: 9351126]

Egan TM, North RA. Acetylcholine acts on m2-muscarinic receptors to excite rat locus coeruleus neurones. Br J Pharmacol 1985;85:733-735. [PubMed: 3840044]

Egan TM, North RA. Acetylcholine hyperpolarizes central neurones by acting on an M2 muscarinic receptor. Nature 1986;319:405-407. [PubMed: 2418362]

Farber J, Marks GA, Roffwarg HP. Rapid eye movement sleep PGO-type waves are present in the dorsal pons of the albino rat. Science 1980;209:615-617. [PubMed: 6994229] 
Frank MG, Heller HC. Development of REM and slow wave sleep in the rat. Am J Physiol 1997;272:R1792-R1799. [PubMed: 9227592]

Gerber U, Greene RW, McCarley RW. Repetitive firing properties of medial pontine reticular formation neurones of the rat recorded in vitro. J Physiol 1989;410:533-560. [PubMed: 2795489]

Gerber U, Stevens DR, McCarley RW, Greene RW. Muscarinic agonists activate an inwardly rectifying potassium conductance in medial pontine reticular formation neurons of the rat in vitro. $\mathrm{J}$ Neurosci 1991;11:3861-3867. [PubMed: 1744694]

Gnadt JW, Pegram GV. Cholinergic brainstem mechanisms of REM sleep in the rat. Brain Res 1986;384:29-41. [PubMed: 3790997]

Greco MA, Shiromani PJ. Hypocretin receptor protein and mRNA expression in the dorsolateral pons of rats. Brain Res Mol Brain Res 2001;88:176-182. [PubMed: 11295245]

Greene RW, Gerber U, McCarley RW. Cholinergic activation of medial pontine reticular formation neurons in vitro. Brain Res 1989;476:154-159. [PubMed: 2914210]

Greene RW, Haas HL, McCarley RW. A low threshold calcium spike mediates firing pattern alterations in pontine reticular neurons. Science 1986;234:738-740. [PubMed: 3775364]

Hajnik T, Lai YY, Siegel JM. Atonia-related regions in the rodent pons and medulla. J Neurophysiol 2000;84:1942-1948. [PubMed: 11024087]

Horvath TL, Peyron C, Diano S, Ivanov A, Aston JG, Kilduff TS, Van-den Pol A. Hypocretin (orexin) activation and synaptic innervation of the locus coeruleus noradrenergic system. J Comp Neurol 1999;415:145-159. [PubMed: 10545156]

Jouvet M. Recherches sur les structures nerveuses et les mecanismes responsables des differentes phases du sommeil physiologique. Arch Ital Biol 1962;100:125-206. [PubMed: 14452612]

Kamondi A, Williams JA, Hutcheon B, Reiner PB. Membrane properties of mesopontine cholinergic neurons studied with the whole-cell patch-clamp technique: implications for behavioral state control. J Neurophysiol 1992;68:1359-1372. [PubMed: 1359028]

Karlsson KA, Blumberg MS. Active medullary control of atonia in week-old rats. Neuroscience 2005;130:275-283. [PubMed: 15561443]

Karlsson KA, Gall AJ, Mohns EJ, Seelke AM, Blumberg MS. The neural substrates of infant sleep in rats. PLoS Biol 2005;3:e143. [PubMed: 15826218]

Kaufman LS, Morrison AR. Spontaneous and elicited PGO spikes in rats. Brain Res 1981;214:61-72. [PubMed: 7237166]

Kiyashchenko LI, Mileykovskiy BY, Lai YY, Siegel JM. Increased and decreased muscle tone with orexin (hypocretin) microinjections in the locus coeruleus and pontine inhibitory area. J Neurophysiol 2001;85:2008-2016. [PubMed: 11353017]

Lancaster B, Adams PR. Calcium-dependent current generating the afterhyperpolarization of hippocampal neurons. J Neurophysiol 1986;55:1268-1282. [PubMed: 2426421]

Leonard CS, Llinas R. Serotonergic and cholinergic inhibition of mesopontine cholinergic neurons controlling REM sleep: an in vitro electrophysiological study. Neuroscience 1994;59:309-330. [PubMed: 8008195]

Liu RJ, van den Pol AN, Aghajanian GK. Hypocretins (orexins) regulate serotonin neurons in the dorsal raphe nucleus by excitatory direct and inhibitory indirect actions. J Neurosci 2002;22:9453-9464. [PubMed: 12417670]

Luebke JI, Greene RW, Semba K, Kamondi A, McCarley RW, Reiner PB. Serotonin hyperpolarizes cholinergic low-threshold burst neurons in the rat laterodorsal tegmental nucleus in vitro. Proc Natl Acad Sci U S A 1992;89:743-747. [PubMed: 1731349]

Lydic R, Baghdoyan HA, Lorinc Z. Microdialysis of cat pons reveals enhanced acetylcholine release during state-dependent respiratory depression. Am J Physiol 1991;261:R766-R770. [PubMed: 1887963]

Magistretti J, Mantegazza M, Guatteo E, Wanke E. Action potentials recorded with patch-clamp amplifiers: are they genuine? Trends Neurosci 1996;19:530-534. [PubMed: 8961481]

Marks GA, Farber J, Roffwarg HP. Metencephalic localization of ponto-geniculo-occipital waves in the albino rat. Exp Neurol 1980;69:667-677. [PubMed: 7409068] 
Mavanji V, Datta S. Activation of the phasic pontine-wave generator enhances improvement of learning performance: a mechanism for sleep-dependent plasticity. Eur J Neurosci 2003;17:359-370. [PubMed: 12542673]

McCarley RW. Mechanisms and models of REM sleep control. Arch Ital Biol 2004;142:429-467. [PubMed: 15493547]

McCarley RW, Ito K. Intracellular evidence linking medial pontine reticular formation neurons to PGO wave generation. Brain Res 1983;280:343-348. [PubMed: 6652494]

McCarley RW, Nelson JP, Hobson JA. Ponto-geniculo-occipital (PGO) burst neurons: correlative evidence for neuronal generators of PGO waves. Science 1978;201:269-272. [PubMed: 663656]

McCarley RW, Winkelman JW, Duffy FH. Human cerebral potentials associated with REM sleep rapid eye movements: links to PGO waves and waking potentials. Brain Res 1983;274:359-364. [PubMed: 6626965]

Mitler MM, Dement WC. Cataplectic-like behavior in cats after micro-injections of carbachol in pontine reticular formation. Brain Res 1974;68:335-343. [PubMed: 4857063]

Morrison AR. Paradoxical sleep without atonia. Arch Ital Biol 1988;126:275-289. [PubMed: 3058081]

Mouret J, Delorme F, Jouvet M. [Lesions of the pontine tegmentum and sleep in rats]. C R Seances Soc Biol Fil 1967;161:1603-1606. [PubMed: 4231637]

Nelson JP, McCarley RW, Hobson JA. REM sleep burst neurons, PGO waves, and eye movement information. J Neurophysiol 1983;50:784-797. [PubMed: 6631463]

Notomi T, Shigemoto R. Immunohistochemical localization of Ih channel subunits, HCN1-4, in the rat brain. J Comp Neurol 2004;471:241-276. [PubMed: 14991560]

Nunez A, De la RC, Rodrigo-Angulo ML, Buno W, Reinoso-Suarez F. Electrophysiological properties and cholinergic responses of rat ventral oral pontine reticular neurons in vitro. Brain Res 1997;754:111. [PubMed: 9134953]

Pare D, Curro DR, Datta S, Steriade M. Brainstem genesis of reserpine-induced ponto-geniculo-occipital waves: an electrophysiological and morphological investigation. Exp Brain Res 1990;81:533-544. [PubMed: 2226686]

Paxinos, G.; Carrive, P.; Wang, H.; Wang, P-Y. Chemoarchitectonic atlas of the rat brainstem. San Diego, CA, USA: Academic Press; 1999.

Paxinos, G.; Watson, C. The rat brain in stereotaxic coordinates. San Diego, CA: Academic Press; 1998.

Peyron C, Tighe DK, van-den Pol AN, de LL, Heller HC, Sutcliffe JG, Kilduff TS. Neurons containing hypocretin (orexin) project to multiple neuronal systems. J Neurosci 1998;18:9996-10015. [PubMed: 9822755]

Pollock MS, Mistlberger RE. Rapid eye movement sleep induction by microinjection of the GABA-A antagonist bicuculline into the dorsal subcoeruleus area of the rat. Brain Res 2003;962:68-77. [PubMed: 12543457]

Rainnie DG, Grunze HC, McCarley RW, Greene RW. Adenosine inhibition of mesopontine cholinergic neurons: implications for EEG arousal. Science 1994;263:689-692. [PubMed: 8303279]

Sakai K, Jouvet M. Brain stem PGO-on cells projecting directly to the cat dorsal lateral geniculate nucleus. Brain Res 1980;194:500-505. [PubMed: 7388627]

Sakai K, Koyama Y. Are there cholinergic and non-cholinergic paradoxical sleep-on neurones in the pons? Neuroreport 1996;7:2449-2453. [PubMed: 8981401]

Sanford LD, Cheng CS, Silvestri AJ, Tang X, Mann GL, Ross RJ, Morrison AR. Sleep and behaviour in rats with pontine lesions producing REM without atonia. Sleep Res Online 2001;4:1-5.

Sanford LD, Yang L, Tang X, Ross RJ, Morrison AR. Tetrodotoxin inactivation of pontine regions: influence on sleep-wake states. Brain Res 2005;1044:42-50. [PubMed: 15862788]

Seelke AM, Karlsson KA, Gall AJ, Blumberg MS. Extraocular muscle activity, rapid eye movements and the development of active and quiet sleep. Eur J Neurosci 2005;22:911-920. [PubMed: 16115214]

Spruston N, Jaffe DB, Johnston D. Dendritic attenuation of synaptic potentials and currents: the role of passive membrane properties. Trends Neurosci 1994;17:161-166. [PubMed: 7517596] 
Steriade M, Pare D, Datta S, Oakson G, Curro DR. Different cellular types in mesopontine cholinergic nuclei related to ponto-geniculo-occipital waves. J Neurosci 1990;10:2560-2579. [PubMed: 2201752]

Taheri S, Zeitzer JM, Mignot E. The role of hypocretins (orexins) in sleep regulation and narcolepsy. Annu Rev Neurosci 2002;25:283-313. [PubMed: 12052911]

Takakusaki K, Takahashi K, Saitoh K, Harada H, Okumura T, Kayama Y, Koyama Y. Orexinergic projections to the cat midbrain mediate alternation of emotional behavioural states from locomotion to cataplexy. J Physiol 2005;568:1003-1020. [PubMed: 16123113]

Thakkar MM, Ramesh V, Cape EG, Winston S, Strecker RE, McCarley RW. REM sleep enhancement and behavioral cataplexy following orexin (hypocretin)-II receptor antisense perfusion in the pontine reticular formation. Sleep Res Online 1999;2:112-120. [PubMed: 11382892]

Vanni-Mercier G, Debilly G. A key role for the caudoventral pontine tegmentum in the simultaneous generation of eye saccades in bursts and associated ponto-geniculo-occipital waves during paradoxical sleep in the cat. Neuroscience 1998;86:571-585. [PubMed: 9881870]

Vanni-Mercier G, Sakai K, Lin JS, Jouvet M. Mapping of cholinoceptive brainstem structures responsible for the generation of paradoxical sleep in the cat. Arch Ital Biol 1989;127:133-164. [PubMed: 2774793]

Wilcox KS, Grant SJ, Burkhart BA, Christoph GR. In vitro electrophysiology of neurons in the lateral dorsal tegmental nucleus. Brain Res Bull 1989;22:557-560. [PubMed: 2713729]

Williams JT, North RA, Shefner SA, Nishi S, Egan TM. Membrane properties of rat locus coeruleus neurones. Neuroscience 1984;13:137-156. [PubMed: 6493483]

Xi MC, Chase MH. Neuronal mechanisms of active (rapid eye movement) sleep induced by microinjections of hypocretin into the nucleus pontis oralis of the cat. Neuroscience 2006;140:335342. [PubMed: 16533574]

Xi MC, Fung SJ, Yamuy J, Morales FR, Chase MH. Induction of active (REM) sleep and motor inhibition by hypocretin in the nucleus pontis oralis of the cat. J Neurophysiol 2002;87:2880-2888. [PubMed: 12037191]

Yamamoto K, Mamelak AN, Quattrochi JJ, Hobson JA. A cholinoceptive desynchronized sleep induction zone in the anterodorsal pontine tegmentum: locus of the sensitive region. Neuroscience 1990;39:279-293. [PubMed: 2087260] 
$-9.30$

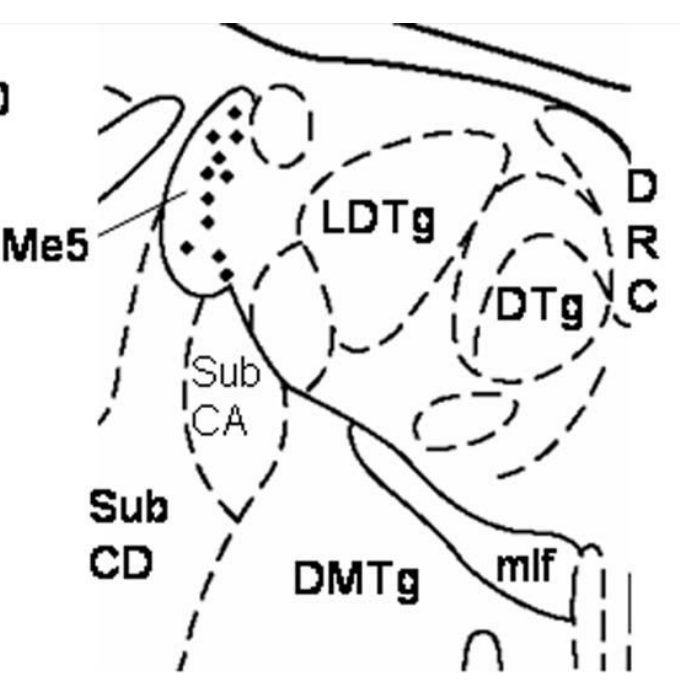

$-9.68$

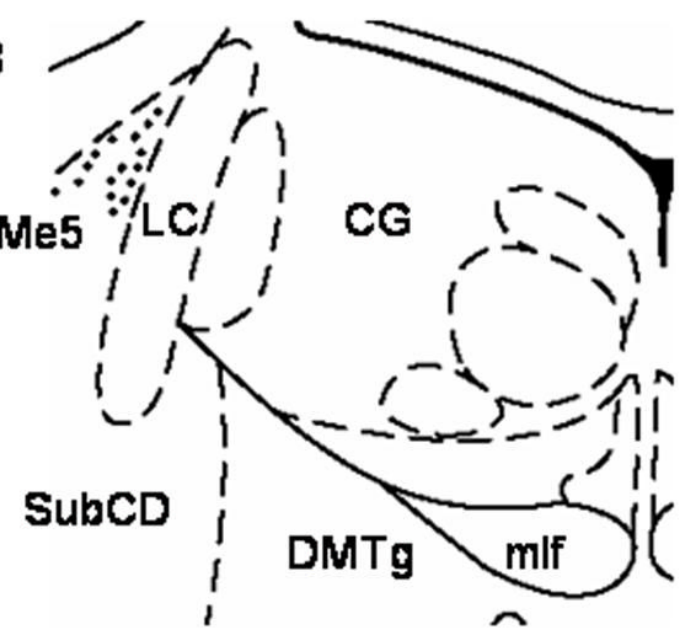

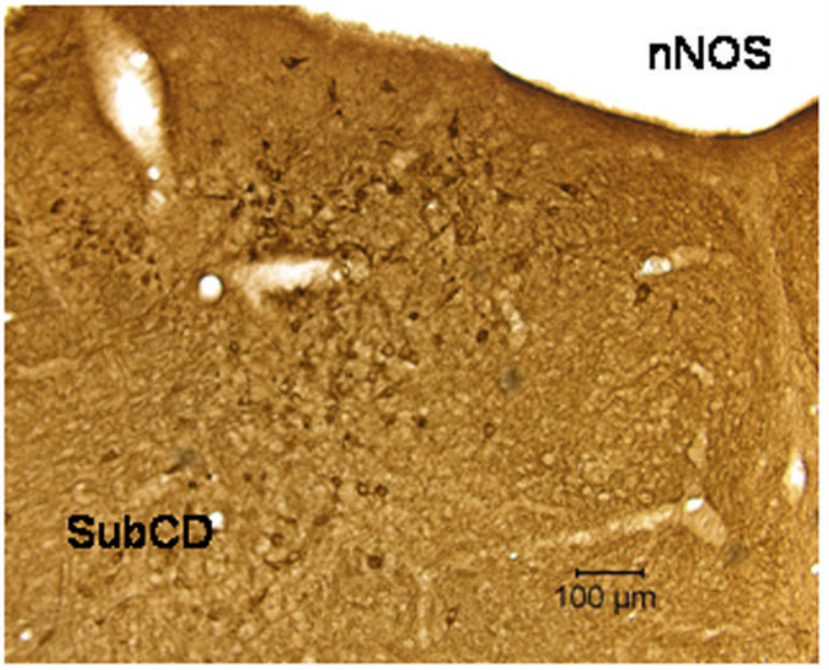

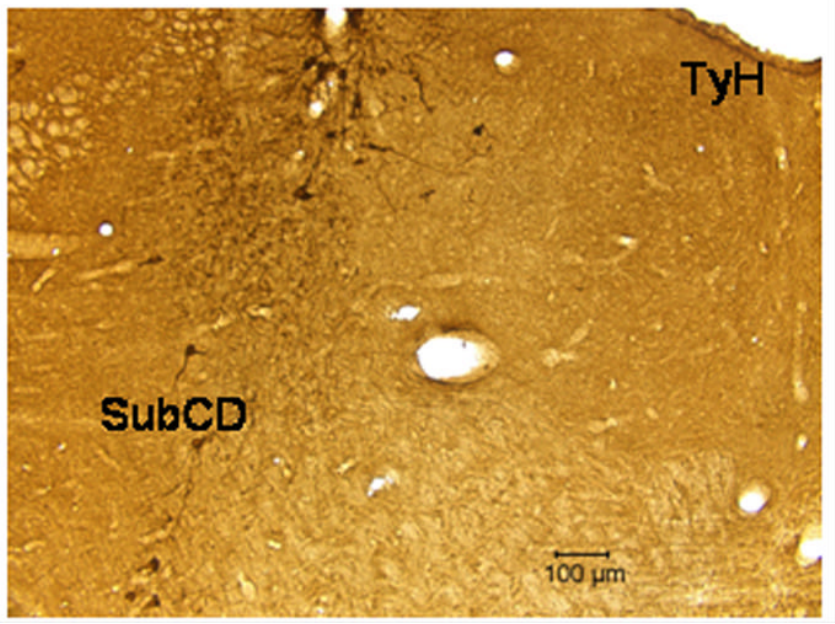

Figure 1.

Neuroanatomy of the rat subcoeruleus (SubC) region. Left panels: Schematics of the rostral (top, $-9.30 \mathrm{~mm}$ with respect to Bregma) and caudal (bottom, $-9.68 \mathrm{~mm}$ with respect to Bregma) SubC regions (SubCD + SubCA) adapted from Paxinos and Watson (1998). Black dots represent very large, mesencephalic (Me5) neurons located lateral to the LDTg and LC. Top right: Distribution of mesopontine cholinergic neurons at the level of the rostral SubC revealed using staining for neuronal nitric oxide synthase (nNOS) and diaminobenzidine (DAB) as chromogen. Large, darkly stained cholinergic neurons (nNOS positive) are densely concentrated dorsally in the laterodorsal region (LDTg) in the central gray and are also present more sparsely in the SubC region, ventral to the LDTg. Bottom right: Distribution of mesopontine noradrenaline neurons at the level of the caudal SubC revealed using staining for tyrosine hydroxylase $(\mathrm{TyH})$ with diaminobenzidine (DAB) as chromogen. Large, darkly stained noradrenaline neurons (TyH positive) are present dorsally in the LC. Scattered TyH positive neurons are also present in the SubC region, ventral to the LC. Abbreviations: CG, central gray; DMTg, dorsomedial tegmental area; DRC, dorsal raphe, caudal part; DTg, dorsal tegmental nucleus of Gudden; LC, locus coeruleus; LDTg, laterodorsal tegmental nucleus; Me5, mesencephalic 5 nucleus; mlf, medial longitudinal fasciculus; SubCA, subcoeruleus alpha part; SubCD, subcoeruleus, dorsal part. 


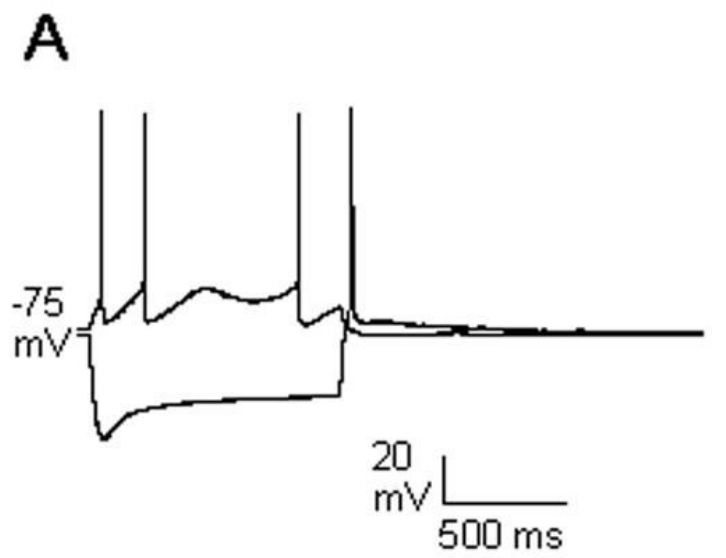

B

C

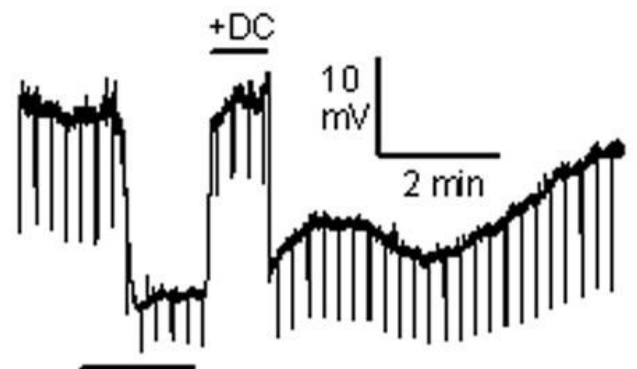

$10 \overline{M C A R B}$

\section{Tetrodotoxin $(0.5 \mu \mathrm{M})$}
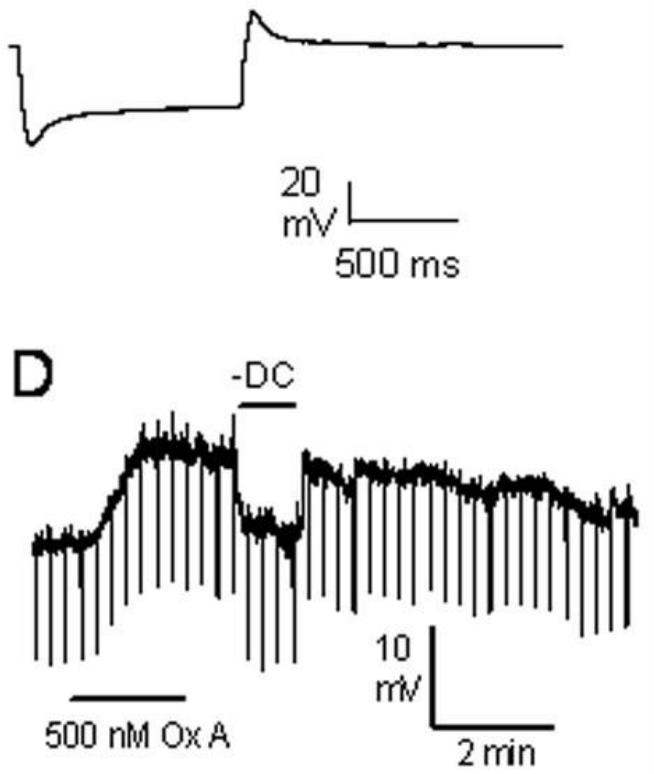

F

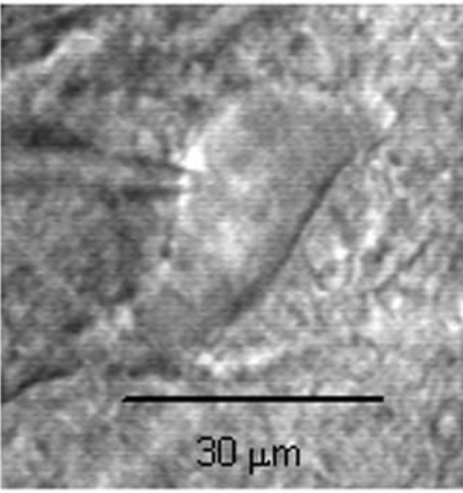

Figure 2.

Properties of large, putative cholinergic neurons in the subcoeruleus region. A: Response to hyperpolarizing and depolarizing current injection in current-clamp. B: Response to hyperpolarizing current injection in the presence of the voltage-gated sodium channel blocker tetrodotoxin. C, D: Continuous recordings of membrane potential in the presence of tetrodotoxin $(0.5 \mu \mathrm{M})$ showing the hyperpolarization caused by carbachol $(\mathrm{CARB}, \mathrm{C})$ and the depolarization caused by orexin A (Ox A, D). Depolarizing (+DC) or hyperpolarizing current injection (-DC) was used to return the membrane potential to the baseline in order to assess the effects of the drugs on input resistance, as assessed by the voltage responses to short (500 ms) hyperpolarizing current steps (downward deflections). E: Slow voltage ramps from -30 
to $-110 \mathrm{mV}$ reveal that the current induced by the cholinergic agonist carbachol (CARB) is outward at the resting membrane potential $(-75 \mathrm{mV})$ and reverses around the equilibrium potential for potassium $(-100 \mathrm{mV})$. F: Infra-red differential interference contrast (IR-DIC) image of the recording pipette and neuron for one neuron of this class whose responses are shown in $\mathrm{A}, \mathrm{B}$ and $\mathrm{E}$. 

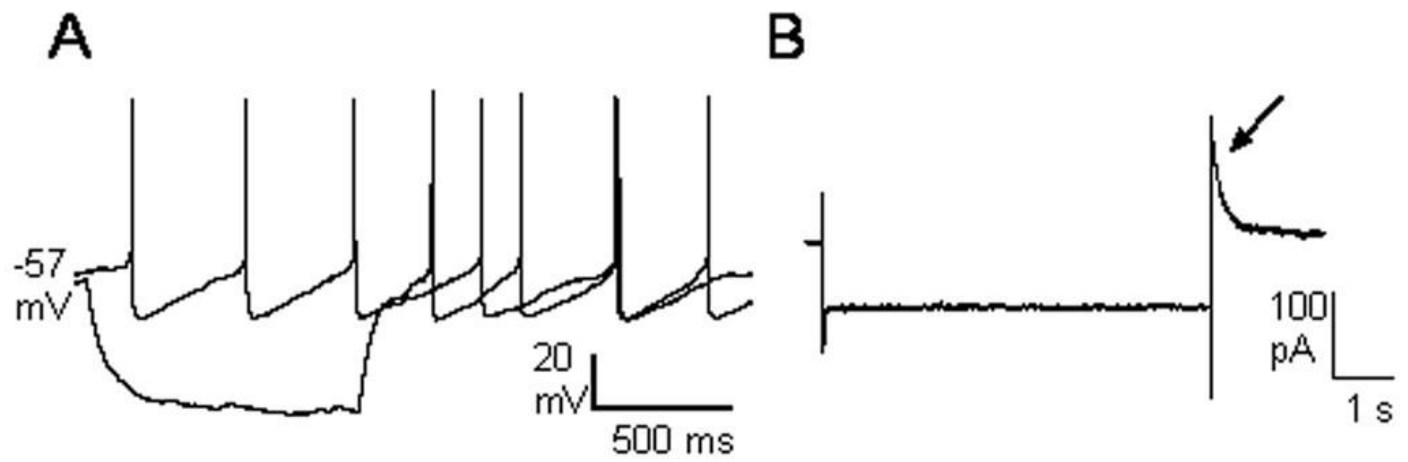

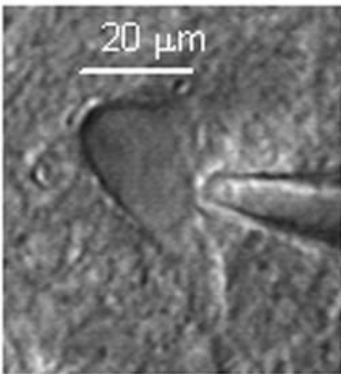

IR-DIC

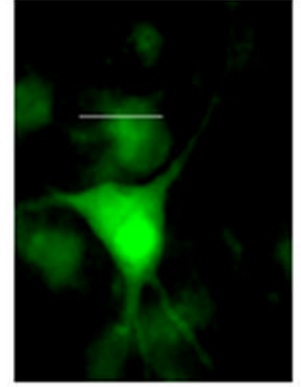

Lucifer Yellow (LV)

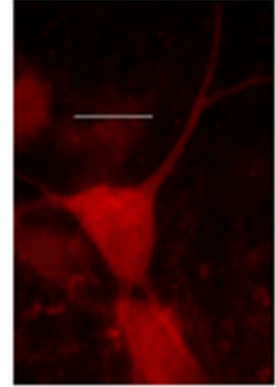

Tyrosine Hydroxylase (TyH)

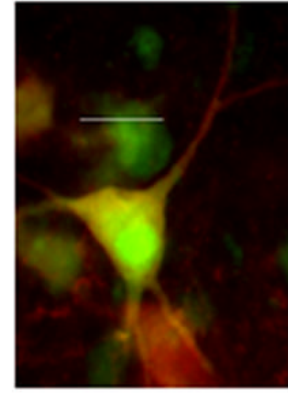

$\mathrm{LY}+\mathrm{T} y \mathrm{H}$
$\mathrm{D}$

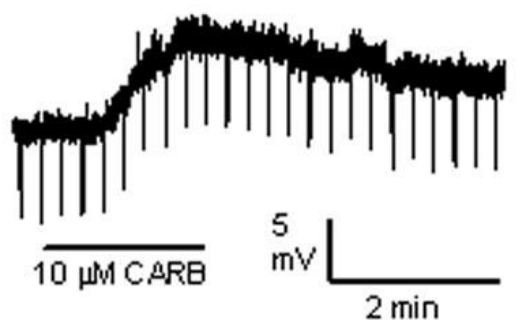

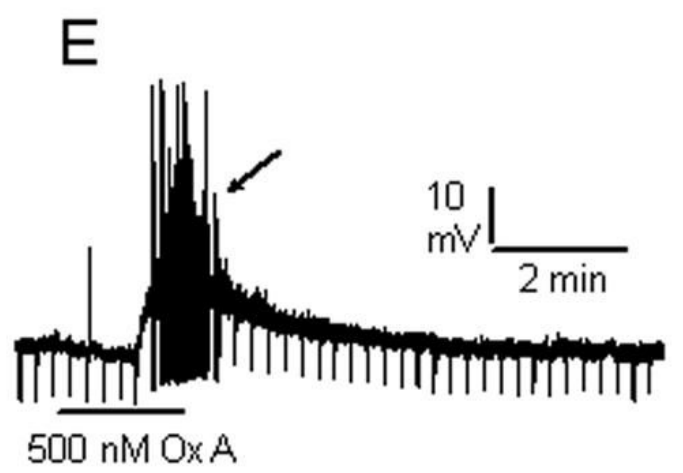

$500 \mathrm{nM} \mathrm{OXA}$

Figure 3.

Properties of tyrosine hydroxylase (TyH) positive neurons in the subcoeruleus region. A: Response to hyperpolarizing current injection and spontaneous firing in current-clamp. B: Response to a hyperpolarizing voltage step in voltage-clamp in the presence of the voltagegated sodium channel blocker tetrodotoxin. Note the transient outward current (arrow) at the offset of the step. C: Infra-red differential interference contrast (IR-DIC) image of the recording pipette and neuron for one neuron of this class whose responses are shown in A, B. This same neuron was filled with the dye Lucifer Yellow. Post-hoc staining revealed that this neuron was TyH positive. D, E: Continuous recordings of membrane potential in the presence of tetrodotoxin $(0.5 \mu \mathrm{M})$ showing the depolarizations caused by carbachol (CARB, D) and orexin 
A (Ox A, E). Input resistance was assessed by the voltage responses to short (500 ms) hyperpolarizing current steps (downward deflections). 

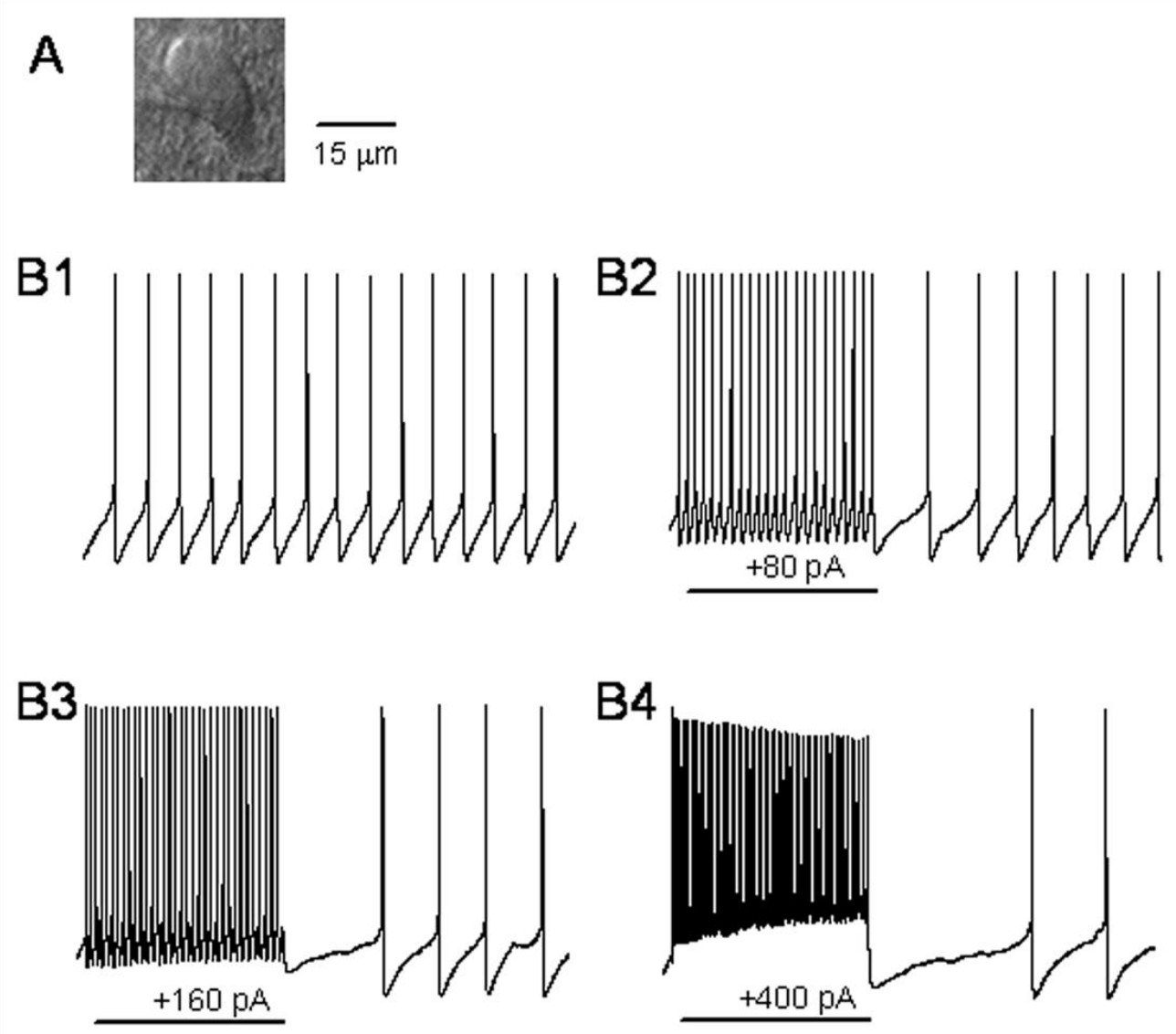

B5

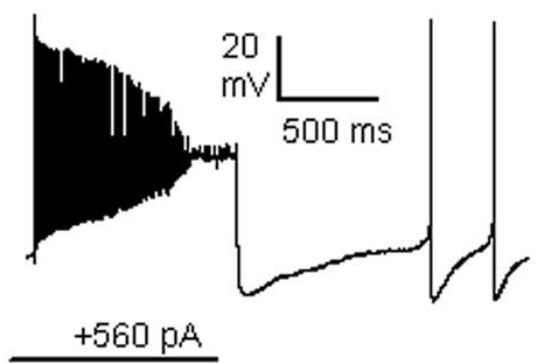

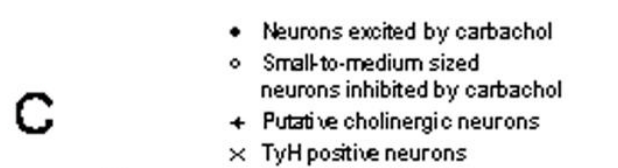

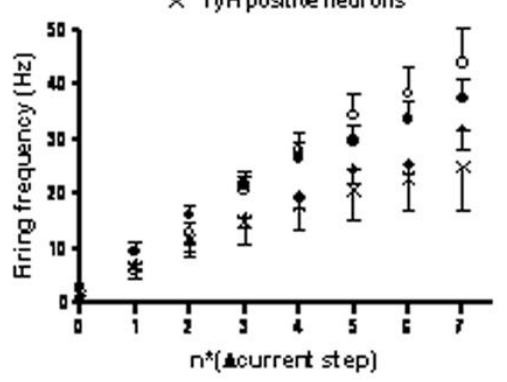

Figure 4.

Response of subcoerulean (SubC) reticular neurons to depolarizing current injection. A: Infrared differential interference contrast (IR-DIC) image of the neuron with the responses depicted in B. B1: this neuron fired spontaneously in the absence of injected current. B2-B5: response to increasing current injection. SubC neurons increased showed increased firing rate without adaptation. During large current pulses inactivation of voltage-gated sodium channels occurred leading to smaller action potentials and/or cessation of firing (B4, B5). Prolonged afterhyperpolarizations proportional to the size of the current step which delayed resumption of firing are also visible at the offset of the depolarizing current injection. C: Current frequency 
plots for different types of neurons found in the SubC. The $\Delta$ current step value was one fifth of the amount of current needed to hyperpolarize the neuron to $-120 \mathrm{mV}$. 

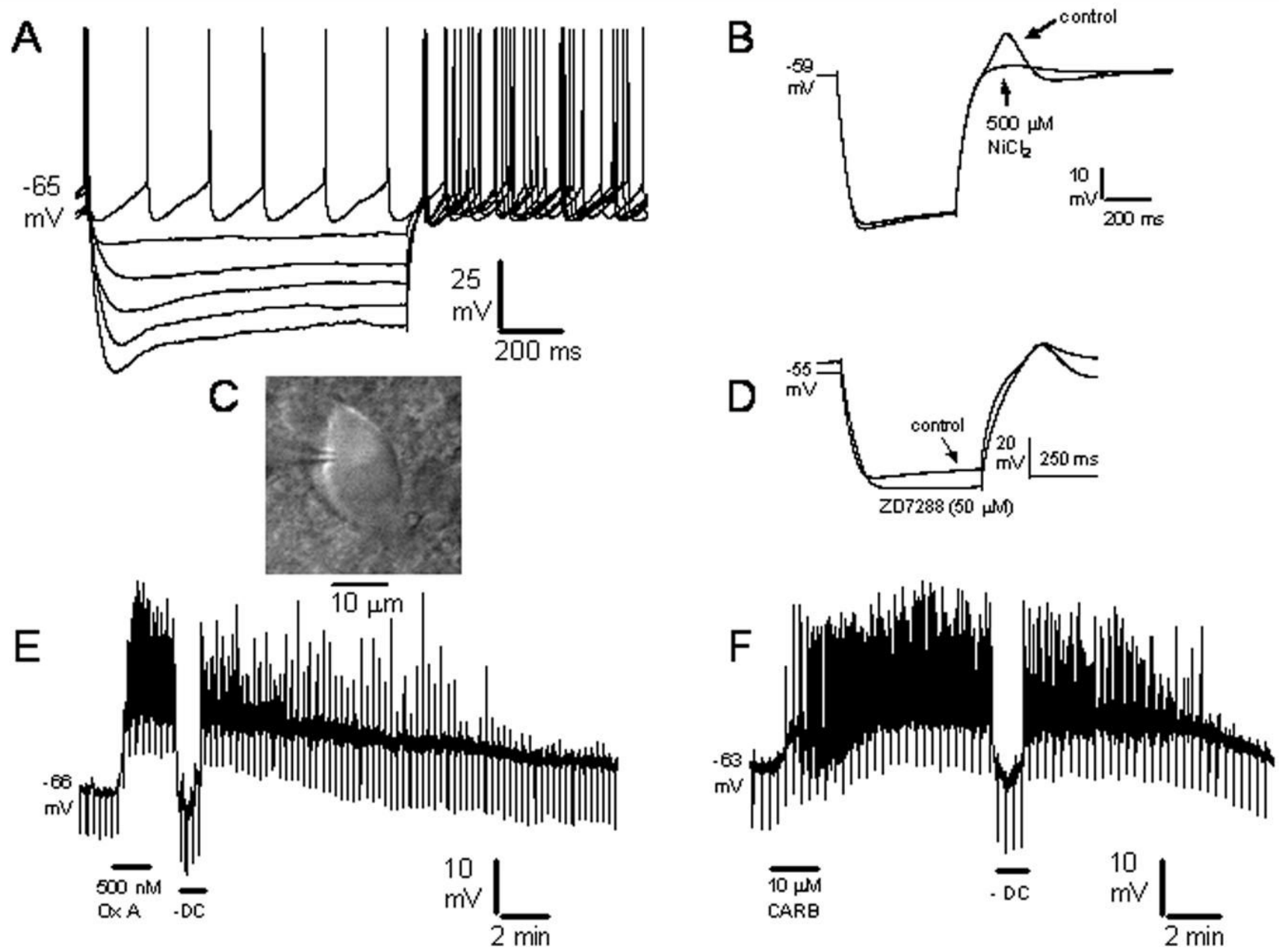

Figure 5.

Properties of SubC reticular neurons excited by carbachol (CARB-E neurons). A: Responses to a series of hyperpolarizing current pulses and spontaneous firing in current-clamp. B: Response to a hyperpolarizing current step in the presence of the voltage-gated sodium channel blocker tetrodotoxin (TTX). Note the rebound depolarization at the offset of the step which is blocked by the calcium channel antagonist nickel chloride (arrow). C: Infrared differential contrast (IR-DIC) image of the recording pipette and neuron for one neuron of this class whose responses are shown in A, B, D-F. D: Response to hyperpolarizing current in the presence of the voltage-gated sodium channel blocker tetrodotoxin. Note the depolarizing sag during the step which is blocked by the H-current blocker ZD7288. E, F: Continuous recordings of membrane potential in the presence of tetrodotoxin $(0.5 \mu \mathrm{M})$ showing the depolarizations caused by orexin A (Ox A, E) and carbachol (CARB, F). Note the high-amplitude calcium spikes (upward deflections) at the peaks of the depolarizations caused by orexin A or carbachol. Hyperpolarizing current injection (-DC) was used to return the membrane potential to the baseline in order to assess the effects of the drugs on input resistance, as assessed by the voltage responses to short $(500 \mathrm{~ms})$ hyperpolarizing current steps (downward deflections). 


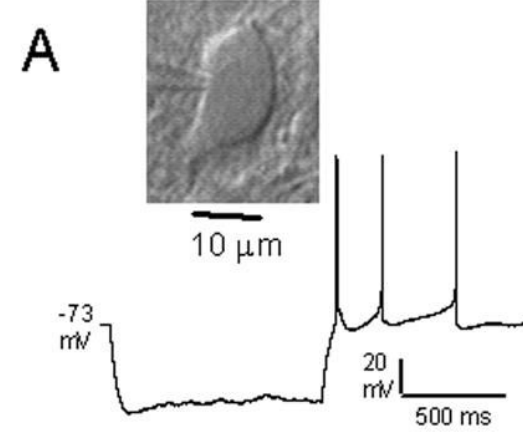

C

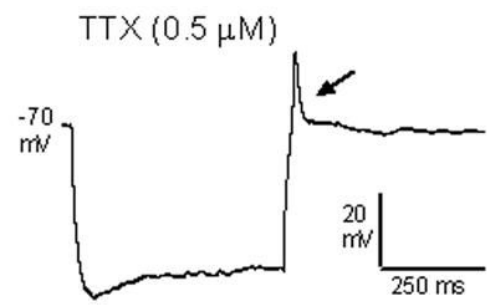

E

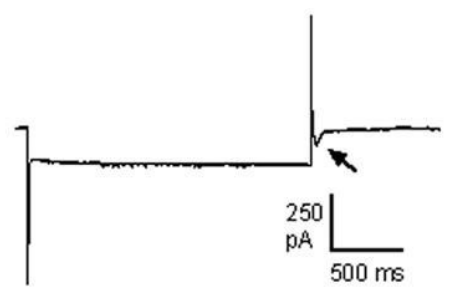

B

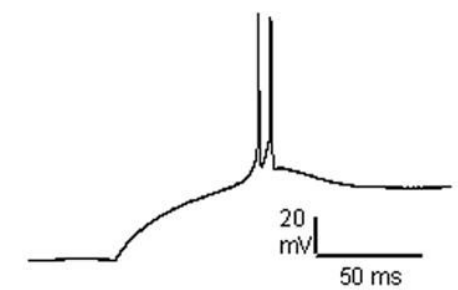

D $\mathrm{TTX}+\mathrm{NiCl}_{2}(500 \mu \mathrm{M})$
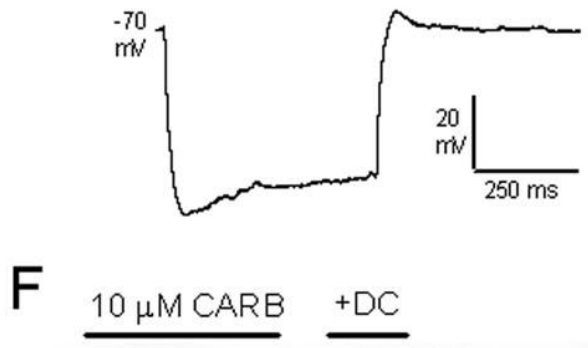

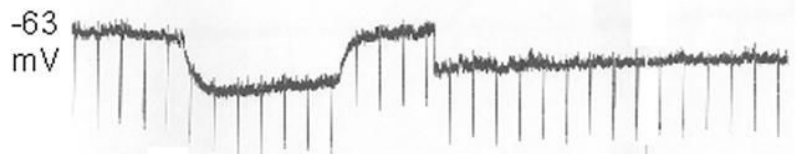

$$
\operatorname{mV}^{10} \frac{L_{1 \mathrm{~min}}}{\mathrm{~m}}
$$

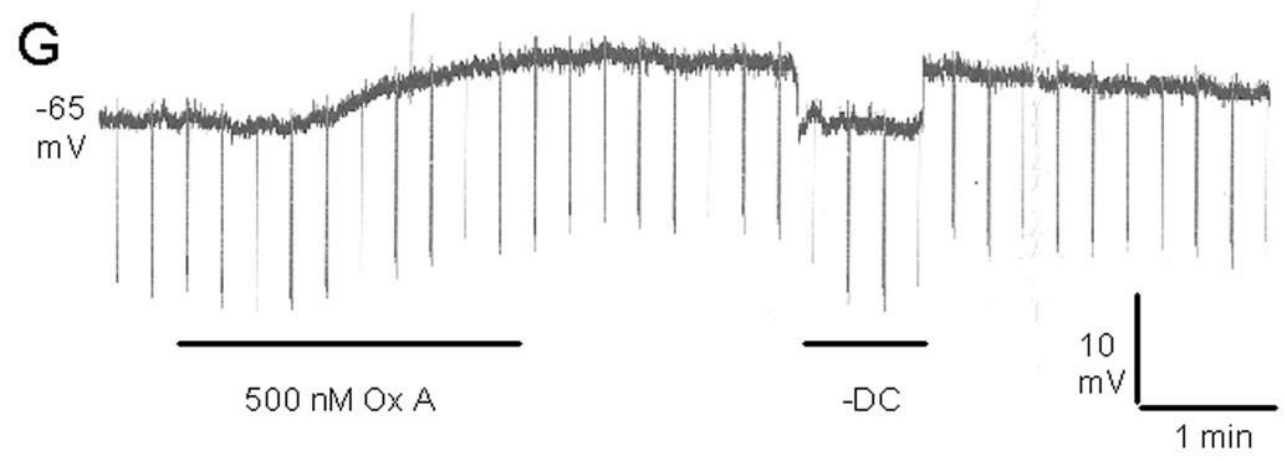

Figure 6.

Properties of SubC reticular neurons inhibited by carbachol and possessing a large lowthreshold spike (CARB-I LTS neurons). A: Response to hyperpolarizing current injection in current-clamp. Inset: Infra-red differential interference contrast (IR-DIC) image of the recording pipette and neuron for one neuron of this class. B: Expanded view of the voltage response at the offset of the hyperpolarizing step shown in A. Note the doublet of action potentials. C: Response to hyperpolarizing current injection in the presence of the voltagegated sodium channel blocker tetrodotoxin (TTX). Note the large LTS (arrow). D: The LTS is blocked by application of the calcium channel antagonist nickel chloride. E: Current response to a hyperpolarizing voltage step in voltage-clamp. Note the transient inward (T) currrent at 
the offset of the step (arrow). F, G: Continuous chart recordings of membrane potential in the presence of tetrodotoxin $(0.5 \mu \mathrm{M})$ showing the hyperpolarization caused by carbachol (CARB, F) and the depolarization caused by orexin A (Ox A, F). Depolarizing (+DC) or hyperpolarizing current injection (-DC) was used to return the membrane potential to the baseline in order to assess the effects of the drugs on input resistance, as assessed by the voltage responses to short (500 ms) hyperpolarizing current steps (downward deflections). 

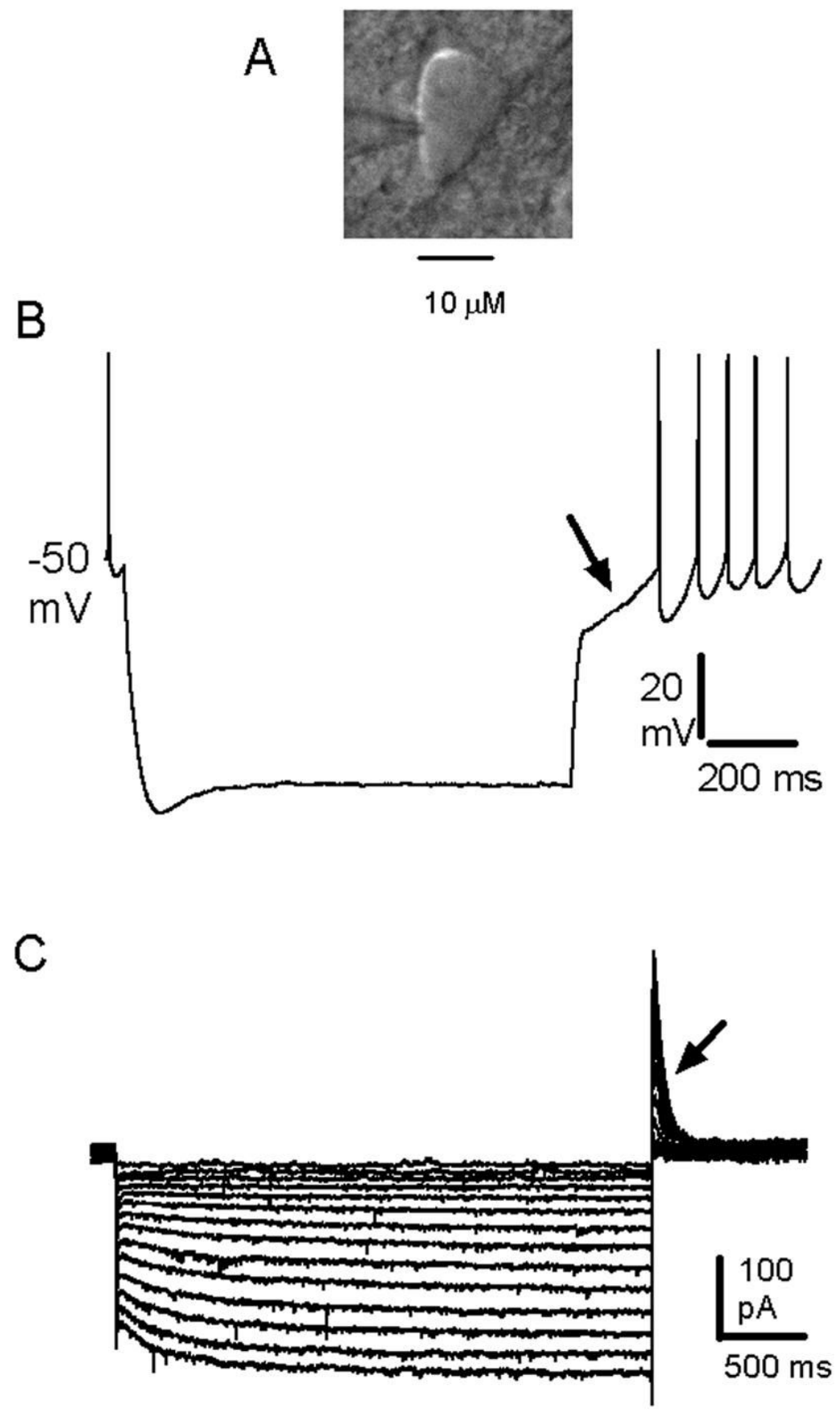

Figure 7.

Intrinsic membrane properties of SubC reticular neurons inhibited by carbachol and possessing a transient outward current (CARB-I A-current neurons). A: C: Infra-red differential interference contrast (IR-DIC) image of the recording pipette and neuron for one neuron of this class whose responses are shown in B, C. B: Response to hyperpolarizing current injection. Note the depolarizing sag during the step and the delayed return to baseline at the offset of the step (arrow). C: Responses to a series of hyperpolarizing voltage steps in voltage-clamp in the presence of the voltage-gated sodium channel blocker tetrodotoxin. Note the inward $(\mathrm{H})$ current during the step and the transient outward (A) current (arrow) at the offset of the step (arrow). 
Table 1

Summary of properties of rat subcoeruleus (SubC) neurons.

\begin{tabular}{|c|c|c|c|c|c|}
\hline & $\begin{array}{l}\text { Putative } \\
\text { cholinergic }(n= \\
\text { 19) }\end{array}$ & $\begin{array}{l}\text { TyH positive (n } \\
=9)\end{array}$ & $\begin{array}{l}\text { CARB-E }(\mathbf{n}= \\
27)\end{array}$ & $\begin{array}{l}\text { CARB-I LTS (n } \\
=22)\end{array}$ & $\begin{array}{l}\text { CARB-I A- } \\
\text { current }(n=8)\end{array}$ \\
\hline $\begin{array}{l}\text { Long-axis diameter }(\mu \mathrm{m}) \\
\text { Short-axis diameter }(\mu \mathrm{m}) \\
\text { RMP }(\mathrm{mV}) \\
\text { Rin }(\mathrm{M} \Omega) \\
\text { AP width }(\mathrm{ms}) \\
\text { AP rise time }(\mathrm{ms}) \\
\text { AP threshold }(\mathrm{mV}) \\
\text { AP height }(\mathrm{mV}) \\
\text { AHP amplitude }(\mathrm{mV}) \\
\text { sAHP amplitude }(\mathrm{mV}) \\
\% \text { Sag } \\
\text { Delay (ms) } \\
\text { LTS amplitude }(\mathrm{mV}) \\
\text { LTS TTP }(\mathrm{ms}) \\
\text { Spontaneous } \mathrm{f}(\mathrm{Hz}) \\
\text { Maximum } \mathrm{f}(\mathrm{Hz}) \\
\text { Effect of CARB }\end{array}$ & $\begin{array}{l}\mathbf{2 9 . 9} \pm \mathbf{1 . 5} \\
14.2 \pm 0.8 \\
-62.2 \pm 1.1 \\
337 \pm 28 \\
3.2 \pm 0.3 \\
0.8 \pm 0.1 \\
-54.1 \pm 1.0 \\
70.5 \pm 4.1 \\
-16.4 \pm 0.9 \\
-12.6 \pm 1.5 \\
\mathbf{5 4 . 1} \pm \mathbf{1 . 8} \\
57 \pm 8 \\
15.7 \pm 1.7 \\
63 \pm 10 \\
2.5 \pm 0.7 \\
43 \pm 4 \\
\text { Inhibition }\end{array}$ & $\begin{array}{l}26.6 \pm 1.6 \\
16.7 \pm 1.1 \\
-60.6 \pm 0.8 \\
411 \pm 95 \\
2.9 \pm 0.9 \\
1.2 \pm 0.4 \\
-48.5 \pm 1.9 \\
61.3 \pm 2.8 \\
-25.1 \pm 1.8 \\
-16.3 \pm 1.5 \\
\mathbf{9 7 . 3} \pm \mathbf{1 . 5} \\
\mathbf{4 7 0} \pm \mathbf{1 2 7} \\
- \\
- \\
1.2 \pm 0.3 \\
39 \pm 6 \\
\text { Excitation }\end{array}$ & $\begin{array}{l}24.7 \pm 1.1 \\
12.9 \pm 0.9 \\
-61.6 \pm 1.1 \\
406 \pm 47 \\
2.7 \pm 0.3 \\
1.1 \pm 0.2 \\
-52.8 \pm 1.8 \\
57.5 \pm 2.5 \\
-19.0 \pm 1.4 \\
-9.1 \pm 0.9 \\
75.0 \pm 1.9 \\
71 \pm 8 \\
12.3 \pm 1.6 \\
\mathbf{1 1 9} \pm \mathbf{1 4} \\
6.5 \pm 0.7 \\
52 \pm 4 \\
\text { Excitation }\end{array}$ & $\begin{array}{l}\mathbf{2 0 . 3} \pm \mathbf{0 . 6} \\
9.8 \pm 0.3 \\
-65.4 \pm 1.5 \\
407 \pm 37 \\
2.5 \pm 0.3 \\
0.9 \pm 0.1 \\
-50.0 \pm 1.1 \\
58.4 \pm 3.1 \\
-16.2 \pm 1.9 \\
-8.0 \pm 0.8 \\
\mathbf{8 3 . 0} \pm \mathbf{2 . 2} \\
58 \pm 6 \\
\mathbf{2 0 . 0} \pm \mathbf{1 . 7} \\
\mathbf{6 4} \pm \mathbf{7} \\
- \\
49 \pm 4 \\
\text { Inhibition }\end{array}$ & $\begin{array}{l}19.0 \pm 1.3 \\
11.0 \pm 1.0 \\
-60.0 \pm 4.0 \\
833 \pm 254 \\
3.7 \pm 0.4 \\
1.4 \pm 0.2 \\
-52.3 \pm 4.0 \\
54.3 \pm 4.8 \\
-14.3 \pm 2.4 \\
-6.5 \pm 2.0 \\
\mathbf{8 2 . 4} \pm \mathbf{1 . 3} \\
\mathbf{2 4 0} \pm \mathbf{3 5} \\
- \\
- \\
5.1 \pm 2.7 \\
32 \pm 3 \\
\text { Inhibition }\end{array}$ \\
\hline
\end{tabular}

Parameters in bold indicate those properties which distinguish each group of neurons. Abbreviations: TyH, Tyrosine hydroxylase; CARB-E, carbachol excited; CARB-I, carbachol inhibited; RMP, resting membrane potential; Rin, input resistance; AP, Action potential; AHP, afterhyperpolarization; sAHP, slow afterhyperpolarization; LTS, low-threshold spike; TTP, time-to-peak; f, firing frequency; CARB, carbachol. 